\title{
Experimental study of the heater size effect on subcooled pool boiling heat transfer of FC-72 in microgravity
}

\author{
Xueli Wang ${ }^{\mathrm{a}}$, Yonghai Zhang ${ }^{\mathrm{b}}$, Baojin Qi ${ }^{\mathrm{b}}$, Jianfu Zhao ${ }^{\mathrm{c}}$, Jinjia Wei ${ }^{\mathrm{b}, *}$ \\ a State Key Laboratory of Multiphase Flow in Power Engineering, Xi'an Jiaotong University, Xi'an 710049, People's Republic of China \\ ${ }^{\mathrm{b}}$ School of Chemical Engineering and Technology, Xi'an Jiaotong University, Xi'an 710049, People's Republic of China \\ ${ }^{\mathrm{c}}$ Key Laboratory of Microgravity (National Microgravity Laboratory)/CAS, Institute of Mechanics, Chinese Academy of Sciences, Beijing 100190, People's Republic of China
}

\section{A R T I C L E I N F O}

\section{Article history:}

Received 29 September 2015

Received in revised form 19 March 2016

Accepted 26 March 2016

Available online 8 April 2016

\section{Keywords:}

Microgravity

Subcooled nucleate boiling performance

Heater size

Nucleate boiling mechanisms

Boiling pattern

\begin{abstract}
A B S T R A C T
Experiments of highly subcooled nucleate pool boiling of FC-72 with dissolved air were conducted on a large scale silicon chip $\left(2 \times 2 \times 0.05 \mathrm{~cm}^{3}\right.$, denoted as chip $\left.\mathrm{S} 2 \times 2\right)$ in short-term microgravity condition and normal gravity condition by utilizing the drop tower in Beijing respectively. The results were compared with published results of a smaller scale chip $\left(1 \times 1 \times 0.05 \mathrm{~cm}^{3}\right.$, denoted as chip $\left.\mathrm{S} 1 \times 1\right)$ both in normal gravity condition and microgravity condition, to study the heater size effect on boiling heat transfer. It is indicated that in microgravity, the input heat flux range in which bubble departure took place for chip S $2 \times 2$ is wider than that for chip S $1 \times 1$, and an interesting phenomenon observed is that coalesced bubbles departed at a continuously smaller radii at a given heat flux. Initially, the average bubble departure radii for chip S $2 \times 2$ increased linearly with heat flux while later remained constant. At a same heat flux, chip $S 2 \times 2$ showed a bubble departure radius larger than that of chip $S 1 \times 1$. By comparison, it is found that nucleate boiling performance deteriorates with increase in heater size in both earth gravity condition and microgravity condition. However, in microgravity the $q_{\mathrm{CHF}}$ of chip S $2 \times 2$ is $20 \%$ greater than that of chip $S 1 \times 1$, contrary to the CHF characteristic in earth ground condition. Moreover, boiling patterns in microgravity are different in high heat flux region: a smooth hemispherical bubble was generated on chip S $1 \times 1$, while on chip S $2 \times 2$ an oblate vapor blanket was formed, which indicates that different dominated boiling heat transfer mechanisms exist in both cases. It is found that in microgravity, the boiling was dominated by buoyancy for chip $S 2 \times 2$, but it was in surface tension dominated boiling regime for chip $S 1 \times 1$, which proved the above speculation. Moreover, the range of transition heater size criteria is $1.45<\frac{L_{\mathrm{h}}}{L_{\mathrm{c}}}<2.89$ in the present work. By using the updated model developed by Raj and Kim, it is discovered that predicted values are generally lower than experimental values in both experiments. Moreover, differences were more evident for chip S $2 \times 2$.
\end{abstract}

(c) 2016 Elsevier Inc. All rights reserved.

\section{Introduction}

With the advancement in MEMS processing technology, electronic industry gradually features in high-speed, large buffer memory and miniaturized devices, leading to a rapid increase of power dissipation rate at chip, module and system levels. Moreover, space-based technologies require efficient operation of those products at different gravity levels. The capability to dissipate large heat flux with small temperature differences has drawn significant attention with boiling as an efficient solution to cooling problems. A solid understanding of boiling mechanisms at variable gravitational levels and at different length scales is therefore of paramount importance.

\footnotetext{
* Corresponding author.

E-mail address: jjwei@mail.xjtu.edu.cn (J. Wei).
}

The most suitable parameter to weigh heater size should be bubble departure diameter $D_{\mathrm{d}}$. However, due to difficulties in experimental measurement and large bias between values obtained based on different correlations, $D_{\mathrm{d}}$ was replaced by capillary length $L_{\mathrm{c}}$ [1]. The effects of heater size on boiling heat transfer have been proved in many researches. Barkhru [2] found that the classical boiling curve was only observable when $L_{\mathrm{h}} / L_{\mathrm{c}}>0.15$. Henry [3] studied the boiling behavior in a $1.7 \mathrm{~g}_{\mathrm{e}}$ environment ( $g_{\mathrm{e}}$ is gravitational acceleration in terrestrial condition) using three heater sizes. The heat fluxes for the two larger sizes were comparable at the same wall temperature, while a non-departing primary bubble was formed on $0.81 \times 0.81 \mathrm{~mm}^{2}$. The recent experiments conducted by Raj [4] at $1.7 g_{e}$ using three heater sizes are in consistency. Hence, it was concluded that below the particular heater size, boiling is dominated by surface tension and the nucleate boiling curve is heater-size-dependent. When the heater size is 


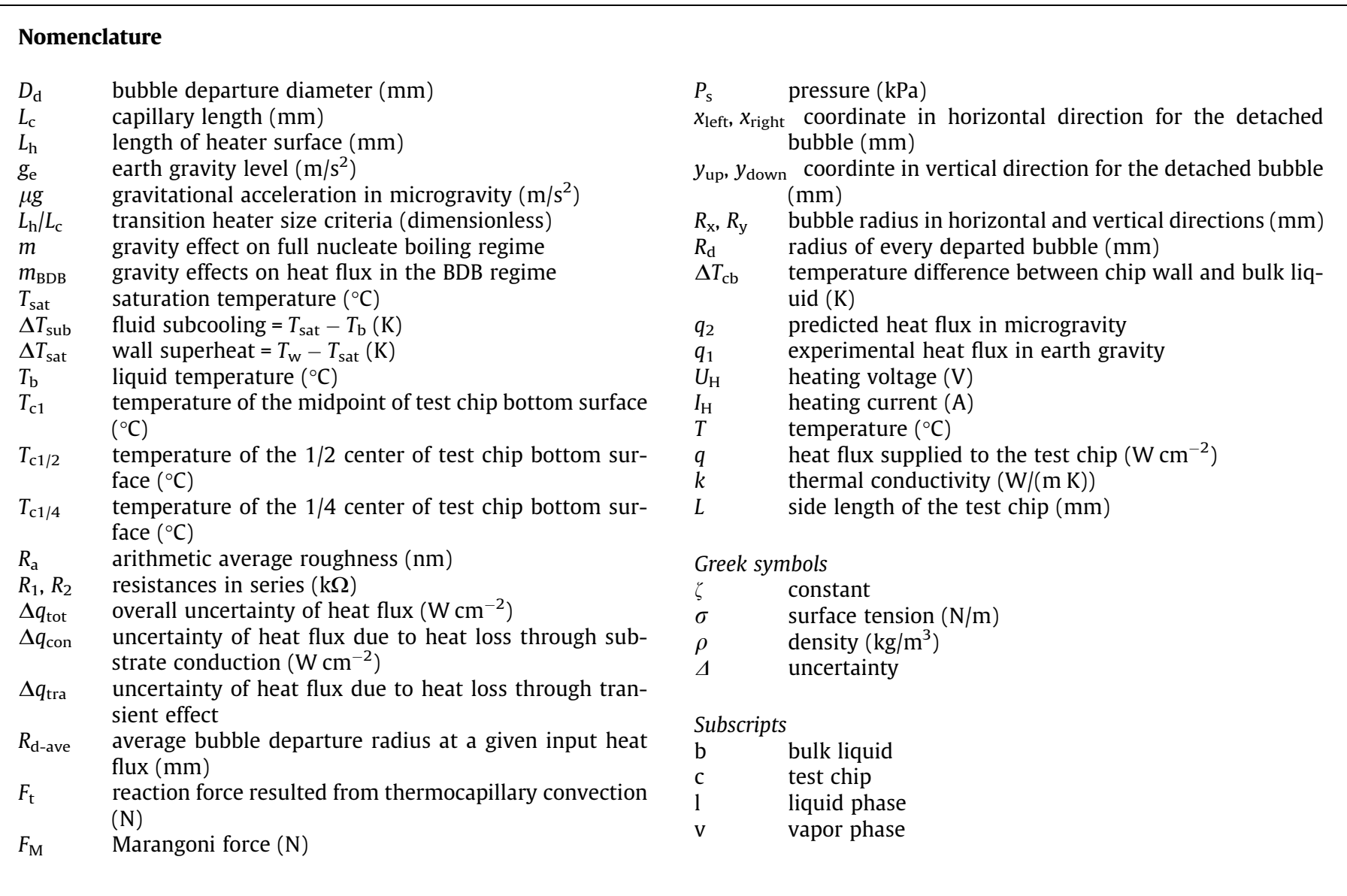

considerably large, boiling is in buoyancy dominated regime, where the boiling curve is independent of heater size.

The gravity levels have a similar effect on boiling heat transfer. Raj [5] found that if the gravitational acceleration is larger than 0.3 $g_{e}$ the heat fluxes for three heater sizes are similar. But for the acceleration values smaller than $0.3 g_{e}$, it is obvious that the heat transfer performance changes with the heater size.

To sum up, boiling is dominated by buoyancy for large heater and/or high gravity level, while the gravity level and/or heater size is declined, surface tension is gradually dominant. The ratio $L_{\mathrm{h}} / L_{\mathrm{c}}$ incorporates the effects of gravity and heater size, so it is a suitable parameter to confirm the transition criterion. Many experiments were conducted to identify the threshold heater size. Raj [6] found that the threshold value of $L_{\mathrm{h}} / L_{\mathrm{c}}$ is about 2.1, above which buoyancy dominates pool boiling heat transfer. Lienhard [7] found the similar result on cylinders.

Until now, many theoretical models and correlations have been developed to predict boiling behavior in earth gravity. However, extensions to lower gravity levels by using those models are unreliable. For example, the correlation of Rosenhow [8] predicts a zero heat flux in the absence of gravity. The correlation developed by Cooper [9] does not have gravity parameter, similarly in the correlation of Stephan [10], the model of Zuber [11] and the correlation of Haramura [12]. Correlations in literature including those mentioned above account for gravity effect on pool boiling in the form of a constant power law coefficient in a wide range of gravity levels. However, Raj [6] found that boiling is in buoyancy dominant regime above $0.1 g_{e}$, where heat flux increases with acceleration. Below $0.1 g_{e}$ surface tension controls boiling, it is less sensitive to gravity. Based on the transition heater size criteria of $\frac{L_{h}}{L_{c}}=2.1$, he proposed the expression for transition acceleration $a_{\text {tran }}$. It is indicated that the use of a constant $m$ for full nucleate boiling regime is incorrect. Oka $[13,14]$ observed that in a low heat flux region the deterioration in heat flux with gravity is negligible $(m \sim 0)$. But at CHF a $30-40 \%$ heat transfer decrease is reported as predicted by the general one-fourth power law $(m=0.25)$. Similarly, Raj et al. [15] proposed that $m_{\mathrm{BDB}}$ which accounts for gravity effects on heat flux in the buoyancy dominated boiling (BDB) regime should vary from 0 at onset of nucleate boiling (ONB) to 0.25 at CHF. Recently, Raj and Kim [16] modified the gravity scaling parameter for heat flux in surface tension dominated boiling (SDB) regime and proposed an updated model.

This paper attempts to study the heater size effect on nucleate boiling heat transfer in both terrestrial gravity condition and shortterm microgravity condition over a smooth silicon chip with dimension of $2 \times 2 \times 0.05 \mathrm{~cm}^{3}$ (denoted as Chip S $2 \times 2$ ). Meanwhile, the results of a small scale chip with dimension of $1 \times 1 \times 0.05 \mathrm{~cm}^{3}$ [17] (denoted as Chip S $1 \times 1$ ) is presented for comparison. The bubble departure radii are analyzed in both experiments, and in the end we compared the experimental and predicted heat flux values in microgravity using the model of Raj and Kim.

\section{Experimental apparatus and test procedures}

\subsection{Experimental apparatus}

A simple but useful pool boiling test facility system for present drop tower experiments is shown schematically in Fig. 1. The boiling chamber with a size of $120 \mathrm{~mm} \times 120 \mathrm{~mm} \times 120 \mathrm{~mm}$ was made of polycarbonate for visualizing boiling phenomena, and was filled with 1.728 L FC-72 with dissolved gas as the test liquid 


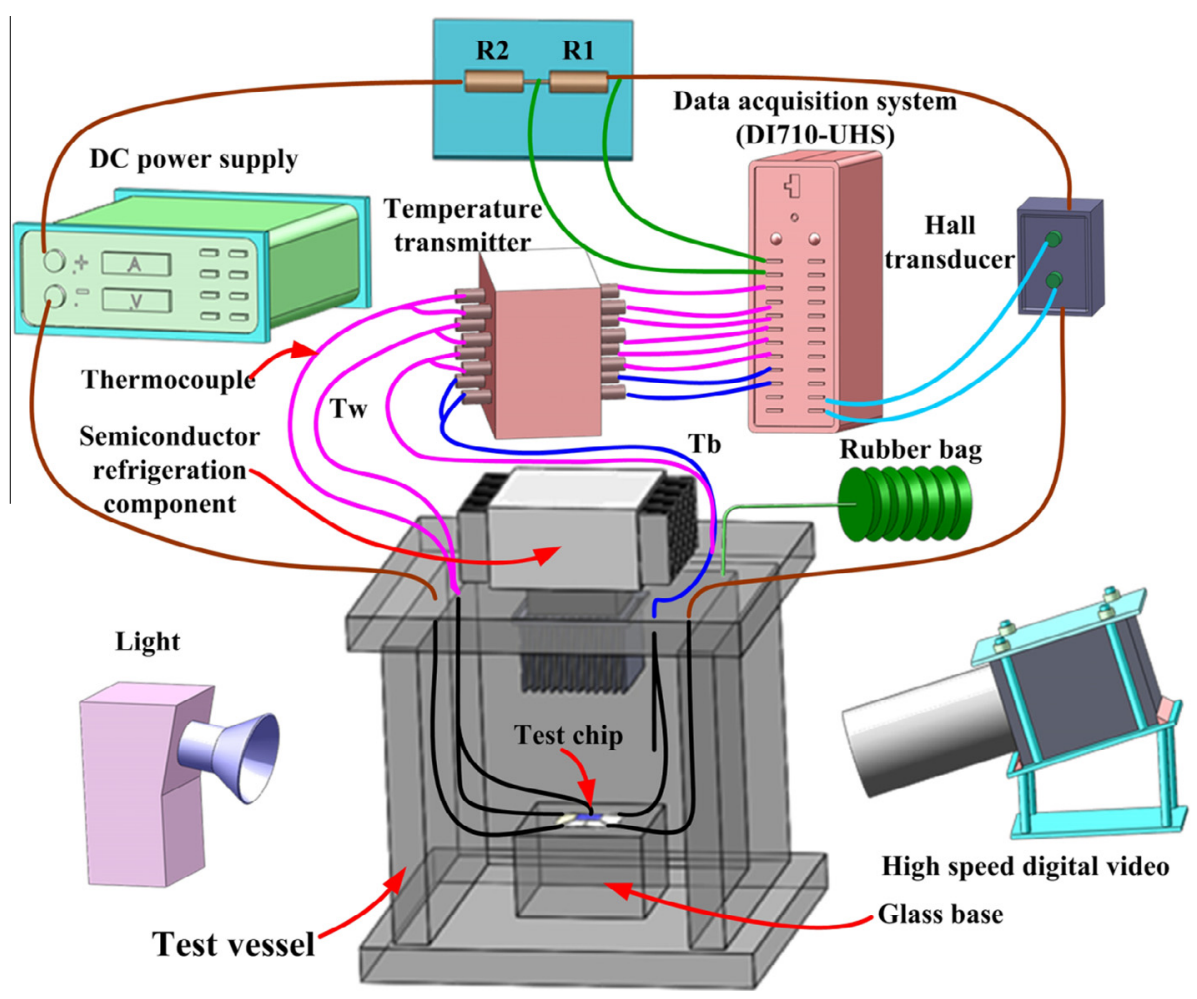

Fig. 1. Schematic diagram of the experimental apparatus.

(the saturation temperature $T_{\text {sat }}$ of $55.7^{\circ} \mathrm{C}$ under atmospheric pressure). In order to maintain a near-atmospheric pressure in the test vessel, a rubber bag was attached to the test vessel. Meanwhile, a semiconductor refrigeration component was mounted on the cover plate of the test vessel to keep the test liquid temperature at the desired value. Having this, the subcooling $\left(\Delta T_{\text {sub }}\right)$ conditions can be adjusted for different experiments. The periodic bubble behaviors including bubble growth, merger and departure processes in different gravity environments were videoed using a $25 \mathrm{~Hz} \mathrm{CCD}$ camera installed in front of the test vessel at an angle of $45^{\circ} \mathrm{C}$ with the heater surface. Simultaneously, a high-speed digital camera (VITcam CTC) imaging 500 frames per second, at a resolution of $1024 \times 640$ pixels, with a shutter speed of $1 / 2000 \mathrm{~s}$ was used having lens (ComputarMLM-3XMP) to image the boiling process.

As the subcooling of bulk fluid has a proved influence on bubble size and critical heat flux in both normal gravity condition and microgravity condition, the accuracy of the test liquid temperature shall not be ignored. A $0.3 \mathrm{~mm}$ diameter T-type thermocouple located at $20 \mathrm{~mm}$ apart from the edge of the test chip and $50 \mathrm{~mm}$ above the chip level to measure the local test liquid temperature $\left(T_{\mathrm{b}}\right)$ with ignoring the bubble dynamics effect. For the higher heat transfer coefficient and the lower heater wall temperature, the wall temperature of heat transfer surface is an important parameter, which directly reveals heat transfer efficiency on the heating wall. Heat transfer performance varies with location on the heater surface, thus three $0.13 \mathrm{~mm}$ diameter T-type thermocouples for corresponding local wall temperature measurements were respectively bonded at the mid-point $\left(T_{\mathrm{c} 1}\right), 1 / 2\left(T_{\mathrm{c} 1 / 2}\right)$ and $1 / 4\left(T_{\mathrm{c} 1 / 4}\right)$ center of the test chip bottom surface, using epoxy adhesive with high thermal conductivity $(5295 \mathrm{~F}, k=1.1 \mathrm{~W} /(\mathrm{m} \mathrm{K})$ ). The locations of thermocouples are shown in Fig. 2a. The input of the data acquisition system is voltage signal, thus the measured temperature values for both heater wall and the bulk fluid must be converted to the corresponding voltage values in advance. Therefore, those aforementioned thermocouples were first connected with a temperature transmitter, and then linked to the data acquisition system as shown in Fig. 1.

A P-doped N-type square smooth silicon chip having dimensions of $20 \mathrm{~mm} \times 20 \mathrm{~mm} \times 0.5 \mathrm{~mm}$ was used for the heater element as shown in Fig. $2 \mathrm{~b}$. The atomic-force-microscope (AFM) image of the chip $S 2 \times 2$ is shown in Fig. 3, which has a very smooth surface with the arithmetic average roughness $\left(R_{\mathrm{a}}\right)$ of $0.276 \mathrm{~nm}$. The nominal resistance of the test chip is $78 \Omega$, specific resistance is $1-3 \Omega \mathrm{cm}$ and thermal conductivity is about $120 \mathrm{~W} /$ $(\mathrm{m} \mathrm{K})$. In this experiment, the chip was Joule heated under a direct voltage by using two $0.25 \mathrm{~mm}$ diameter copper wires soldered with a lower temperature solder (melting at $180^{\circ} \mathrm{C}$ ) to the side surfaces of test chip at the opposite ends. For securing the ohmic contact between the semiconductor silicon chip and copper wire, a special solder with a melting point of $300^{\circ} \mathrm{C}$ was applied to the test chip according to ultrasonic bonding method before soldering cooper wires. Then, the test chip was bonded on a $60 \mathrm{~mm} \times 60 \mathrm{~mm} \times 30 \mathrm{~mm}$ plexiglass base, by using adhesive with very low thermal conductivity of $0.12 \mathrm{~W} /(\mathrm{m} \mathrm{K})$, and the base was fixed on the bottom of test vessel. Because the chip side surfaces were covered with the low thermal conductivity adhesive to minimize heat loss, and the thermal conductivity of plexiglass base is about $1.0886 \mathrm{~W} /(\mathrm{m} \mathrm{K})$, which does not vary with temperature, thus the heat loss to the side and base surfaces of the silicon chip were neglected. Therefore, only the upper surface of the chip was effective for heat transfer. A programmable DC power supply was connected in parallel connection to two resistances in series $\left(R_{1}=5 \mathrm{k} \Omega, R_{2}=100 \mathrm{k} \Omega\right)$ and the test chip. The heating voltage $\left(U_{\mathrm{H}}\right)$ across the silicon chip in the circuit was measured by the above two resistances, while a hall transducer was used to measure the electric current $\left(I_{\mathrm{H}}\right)$ through the silicon chip, ultimately those data were transmitted to a data acquisition system (DI710-UHS).

Due to errors caused by thermocouple calibration by using a platinum resistance thermometer $\left(0.03^{\circ} \mathrm{C}\right)$, the temperature 


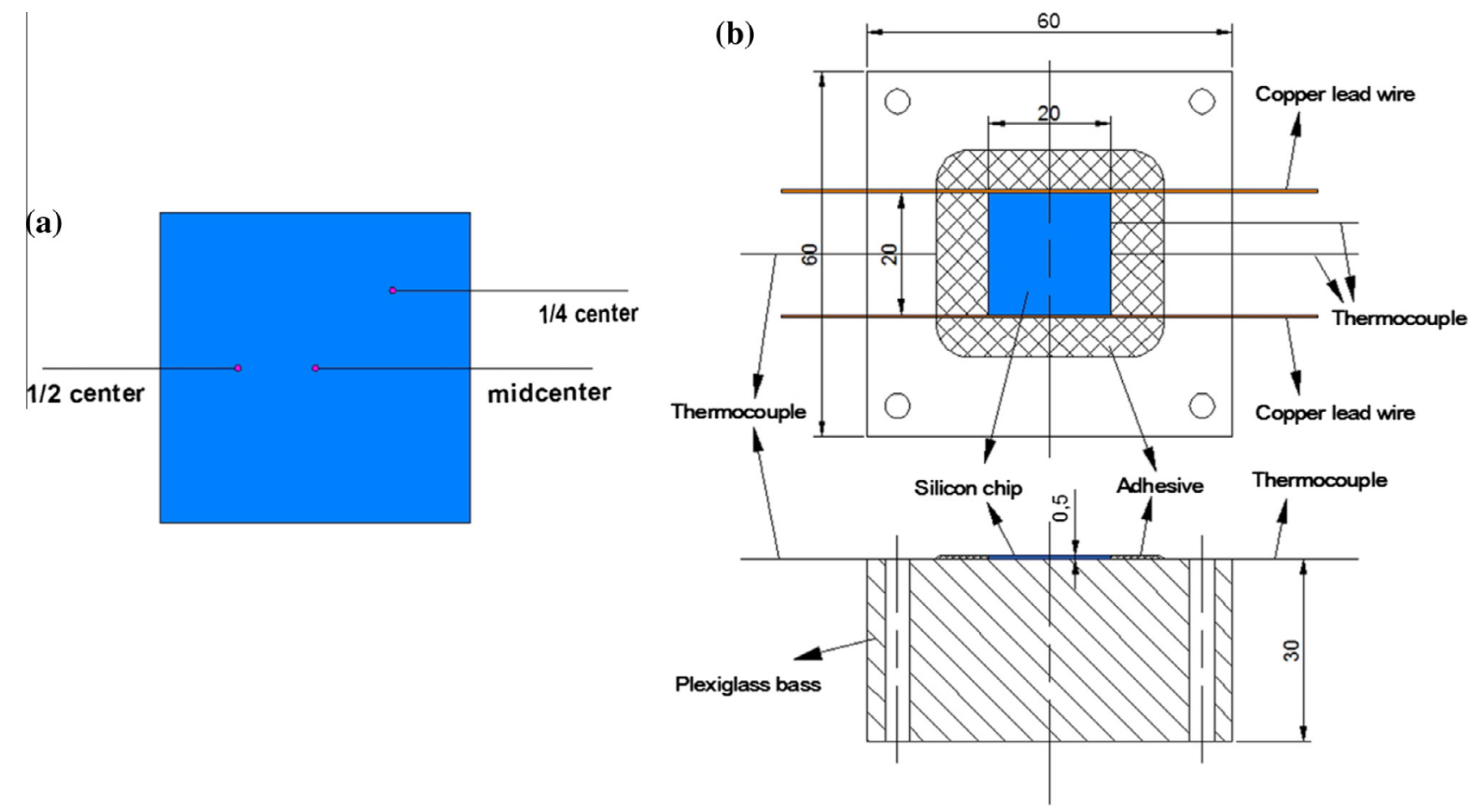

Fig. 2. Locations of thermocouples on the heater wall (a) and the detailed test section (b).

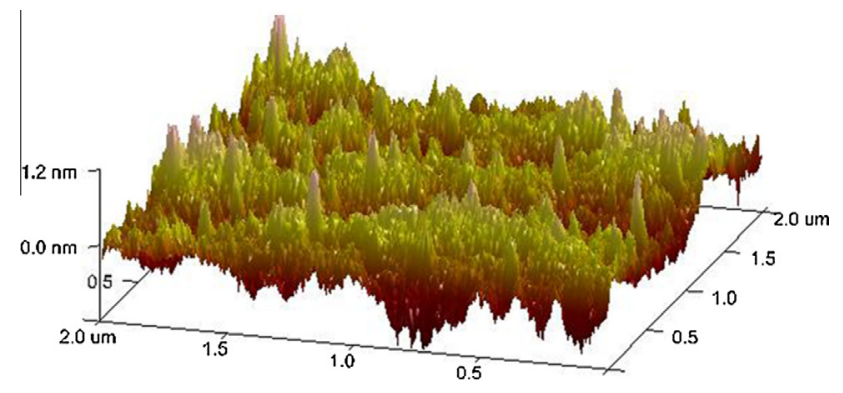

Fig. 3. AFM image of chip $S 2 \times 2, R_{\mathrm{a}}=0.276 \mathrm{~nm}$.

unsteadiness $\left(0.2^{\circ} \mathrm{C}\right)$ and the thermocouple resolution (less than $0.1^{\circ} \mathrm{C}$ ), the uncertainty in bulk liquid temperature measurement using a thermocouple is less than $0.23^{\circ} \mathrm{C}$, calculated as:

$\Delta T=\left(\Delta T_{1}^{2}+\Delta T_{2}^{2}+\Delta T_{3}^{2}+\cdots+\Delta T_{n}^{2}\right)^{1 / 2}$

where $\Delta T_{n}(n=1,2, \ldots, n)$ is the every independent temperature uncertainty. The change of measured bulk liquid temperature is less than $0.5{ }^{\circ} \mathrm{C}$ during each test runs within 90 min approximately. The uncertainty of the measured chip wall temperature is less than $0.25{ }^{\circ} \mathrm{C}$ calculated by Eq. (1), which results from thermocouple calibration by using a platinum resistance thermometer $\left(0.03^{\circ} \mathrm{C}\right)$, temperature correction for obtaining surface temperature on the basis of the measured value at the chip bottom $\left(0.2^{\circ} \mathrm{C}\right)$, temperature fluctuations $\left(0.1^{\circ} \mathrm{C}\right)$ and thermocouple resolution (less than $0.1^{\circ} \mathrm{C}$ ). In this experiment, the general formula for input heat flux calculation is

$q=\frac{U_{\mathrm{H}} I_{\mathrm{H}}}{L^{2}}$

where $L$ is the side length of the test chip. The uncertainty expression of input heat flux is:
$\frac{\Delta q}{q}=\left(\left(\frac{\Delta U_{\mathrm{H}}}{U_{\mathrm{H}}}\right)^{2}+\left(\frac{\Delta I_{\mathrm{H}}}{I_{\mathrm{H}}}\right)^{2}+4\left(\frac{\Delta L}{L}\right)^{2}\right)^{1 / 2}$

where $\Delta U_{\mathrm{H}}, \Delta I_{\mathrm{H}}$ and $\Delta L$ are the uncertainties of heating voltage, heating current and side length of the test chip. The overall uncertainty of heat flux includes heat flux errors in electric power supplied to the per unit chip area, heat loss through substrate conduction and transient effect caused by the change of chip internal energy due to temperature variations, which is calculated as:

$\frac{\Delta q_{\mathrm{tot}}}{q}=\frac{\Delta q_{\mathrm{con}}}{q}+\frac{\Delta q_{\mathrm{tra}}}{q}+\frac{\Delta q}{q}$

where $\Delta q_{\text {tot }}, \Delta q_{\text {con }}, \Delta q_{\text {tra }}$ are the overall uncertainty of heat flux, uncertainty of heat flux due to heat loss through substrate conduction and transient effect. In detail, the measurement uncertainties for $\frac{\Delta U_{\mathrm{H}}}{U_{\mathrm{H}}}, \frac{\Delta I_{\mathrm{H}}}{I_{\mathrm{H}}}$ and $\frac{\Delta L}{L}$ are $0.1 \%, 0.014 \%$ and $0.5 \%$ respectively. The ratio of heat loss through substrate conduction $\frac{\Delta q_{\text {con }}}{q}$ and transient effect $\frac{\Delta q_{\text {tra }}}{q}$ are about $5.0 \%$ and $0.3 \%$. Then the heat flux uncertainty is less than $6 \%$ for steady state boiling heat transfer, and less than $6.3 \%$ for quasi-steady state boiling heat transfer. More detail analyses of the uncertainties were done by Wei [18].

\subsection{Test procedures}

The short-term microgravity condition in the experiment was achieved by releasing the drop capsule in drop tower in the National Microgravity Laboratory, Chinese Academy of Sciences. The facility satisfies the safety criteria for exposing apparatus in drop capsule in different gravitational environments, varying between microgravity ( $\mu \mathrm{g}, 10^{-2}$ to $10^{-3} \mathrm{~g}_{\mathrm{e}}$ ) in the free falling period and high- $g$ level in the deceleration recovery period $\left(16 g_{e}\right)$, where $\mu \mathrm{g}$ is gravitational acceleration in microgravity condition.

The test chip was heated under a set constant input voltage to initiate boiling on the heater wall in terrestrial gravity before the release of drop capsule, and the heat transfer reached a steady state 
after 4 min approximately. Then, free falling of the drop capsule started providing approximately $3.6 \mathrm{~s}$ of effective microgravity environment. During the process, the bubble's behavior both in normal gravity before the release of drop capsule, and microgravity after the release were captured by the high-speed digital video camera working for $8 \mathrm{~s}$, which was divided into two parts by an external trigger signal. The first section $(20 \% \times 8 \mathrm{~s})$ for a time duration about $1.6 \mathrm{~s}$ recorded the bubble's behavior in normal gravity before the release, while those in microgravity after the release were recorded in the other section $(80 \% \times 8 \mathrm{~s})$. Meanwhile, data measurements and video recording were conducted simultaneously.

Because of the limitation in experimental resources, experiment for each heat flux was conducted with only one test run. To make sure the reproducibility and reliability of the experimental data, identical ground experiments were also carried out for comparison. The detail experimental conditions are summarized in Table 1. The bulk liquid subcooling kept at about $41 \mathrm{~K}$, for comparing with previous work by using Chip S $1 \times 1$ [17]. And the corresponding experimental conditions are summarized in Table 2 . The mole fraction of non-condensable gas dissolved concentration in FC-72 was measured by a gas chromatograph, which is same as that measured in previous study i.e. 2600-3300 ppm approximately.

\subsection{Experimental data analysis method}

At a given heat flux, several coalesced bubbles with different radii depart from the heating wall successively in microgravity duration. The statistical bubble departure radii of experimental results were acquired via the following means. As mentioned above, videos of the bubble behaviors were captured by using a high speed digital camera, which could also be saved in BMP format files. Then the picture corresponding bubble detachment moment became convenient to find, and subsequently the AOS Imaging Studio software was employed to read the picture. Based on the image pixel, the coordinates $y_{\text {up }}, y_{\text {down }}$ in vertical direction and coordinates $x_{\text {left }}, x_{\text {right }}$ in horizontal direction for the instantaneous detachment bubble are captured (shown schematically in Fig. 4).

Therefore, the average bubble departure radius is calculated as follows:

$R_{\mathrm{x}}=\frac{x_{\text {right }}-x_{\text {left }}}{2}$

$R_{\mathrm{y}}=\frac{y_{\mathrm{up}}-y_{\text {down }}}{2}$

$R_{\mathrm{d}}=\sqrt{\frac{R_{\mathrm{x}}^{2}+R_{\mathrm{y}}^{2}}{2}}$

$R_{\mathrm{d}-\mathrm{ave}}=\frac{\sum_{1}^{n} R_{\mathrm{d}}}{n}$

where $R_{\mathrm{x}}, R_{\mathrm{y}}$ are the bubble radii in horizontal direction and vertical direction, $R_{\mathrm{d}}$ is the departure radius of every single bubble, and $R_{\mathrm{d}-}$ ave is the arithmetic mean of radii of all these departed bubbles at a given input heat flux. The uncertainties of $R_{\mathrm{x}}, R_{\mathrm{y}}$ and $R_{\mathrm{d}}$ are calculated by Eqs. (9)-(11)

$$
\begin{aligned}
& \Delta R_{\mathrm{X}}=\left(\frac{\Delta x_{\text {right }}^{2}}{4}+\frac{\Delta x_{\text {left }}^{2}}{4}\right)^{1 / 2} \\
& \Delta R_{\mathrm{y}}=\left(\frac{\Delta y_{\text {up }}^{2}}{4}+\frac{\Delta y_{\text {down }}^{2}}{4}\right)^{1 / 2}
\end{aligned}
$$

Table 1

Experimental conditions for chip S $2 \times 2$.

\begin{tabular}{llllll}
\hline Run\# & $\begin{array}{l}\text { Pressure } \\
P_{\mathrm{S}}(\mathrm{kPa})\end{array}$ & $\begin{array}{l}\text { Subcooling } \\
\Delta T_{\text {sub }}(\mathrm{K})\end{array}$ & $\begin{array}{l}\text { Heating } \\
\text { voltage } U_{\mathrm{H}} \\
(\mathrm{V})\end{array}$ & $\begin{array}{l}\text { Heat flux } q \\
\left(\mathrm{~W} \mathrm{~cm}^{-2}\right)\end{array}$ & $\begin{array}{l}\text { Heat } \\
\text { current } I_{\mathrm{H}} \\
(\mathrm{A})\end{array}$ \\
\hline SU43.9 & 101.5 & 40.8 & 43.9 & 4.7 & 0.43 \\
SU57.7 & 102.0 & 42.4 & 57.7 & 7.8 & 0.54 \\
SU72.1 & 102.2 & 40.3 & 72.1 & 11.5 & 0.64 \\
SU83.2 & 101.7 & 39.7 & 83.2 & 14.7 & 0.71 \\
SU91.9 & 103.0 & 40.0 & 91.9 & 17.5 & 0.76 \\
\hline
\end{tabular}

Table 2

Experimental conditions for chip S $1 \times 1$.

\begin{tabular}{ccllll}
\hline Run\# & $\begin{array}{l}\text { Pressure } \\
P_{\mathrm{S}}(\mathrm{kPa})\end{array}$ & $\begin{array}{l}\text { Subcooling } \\
\Delta T_{\text {sub }}(\mathrm{K})\end{array}$ & $\begin{array}{l}\text { Heating } \\
\text { voltage } U_{\mathrm{H}} \\
(\mathrm{V})\end{array}$ & $\begin{array}{l}\text { Heat flux } q \\
\left(\mathrm{~W} \mathrm{~cm}^{-2}\right)\end{array}$ & $\begin{array}{l}\text { Heat } \\
\text { current } I_{\mathrm{H}} \\
(\mathrm{A})\end{array}$ \\
\hline SI0.20 & 102.2 & 40.7 & 16.9 & 3.3 & 0.20 \\
SI0.24 & 101.9 & 41.4 & 20.1 & 4.7 & 0.24 \\
SI0.30 & 101.7 & 40.0 & 24.7 & 7.4 & 0.30 \\
SI0.36 & 102.6 & 41.4 & 32.3 & 11.6 & 0.36 \\
SI0.40 & 102.7 & 40.9 & 36.3 & 14.5 & 0.40
\end{tabular}

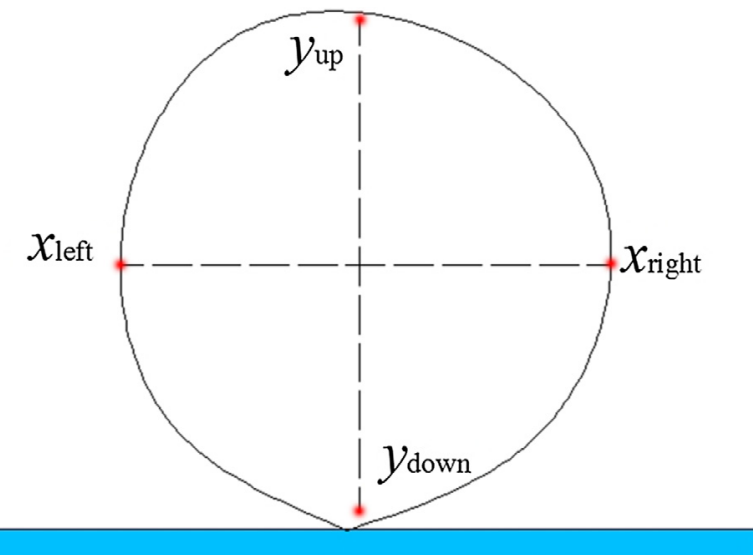

Fig. 4. Schematic diagram of the coordinates in the vertical and horizontal axis for the departed bubble.

$\Delta R_{\mathrm{d}}=\frac{\left(\left(R_{\mathrm{x}} \cdot \Delta R_{\mathrm{x}}\right)^{2}+\left(R_{\mathrm{y}} \cdot \Delta R_{\mathrm{y}}\right)^{2}\right)^{1 / 2}}{2 R_{\mathrm{d}}}$

where $\Delta x_{\text {right }}, \Delta x_{\text {left }}, \Delta y_{\text {up }}, \Delta y_{\text {down }}, \Delta R_{\mathrm{X}}, \Delta R_{\mathrm{y}}$, and $\Delta R_{\mathrm{d}}$ represent the uncertainties in $x_{\text {right }}, x_{\text {left }}, y_{\text {up }}, y_{\text {down }}, R_{\mathrm{X}}, R_{\mathrm{y}}$, and $R_{\mathrm{d}}$, respectively. The measurement uncertainties in our experiment for $\Delta x_{\text {right }}$, $\Delta x_{\text {left }}, \Delta y_{\text {up }}, \Delta y_{\text {down }}$ are $0.01 \mathrm{~mm}, 0.01 \mathrm{~mm}, 0.02 \mathrm{~mm}$, and $0.02 \mathrm{~mm}$ respectively. Therefore the maximum uncertainties of $R_{\mathrm{X}}, R_{\mathrm{y}}, R_{\mathrm{d}}$ and $R_{\mathrm{d} \text {-ave }}$ are less than $0.008 \mathrm{~mm}, 0.015 \mathrm{~mm}, 0.01 \mathrm{~mm}$, and $0.01 \mathrm{~mm}$ respectively.

\section{Results and discussions}

\subsection{Bubbles' behavior and heater wall temperature}

The evolutions of vapor bubble behavior and heater surface temperature on chip $S 2 \times 2$ at different gravity levels and input heat fluxes are shown in Figs. 5 and 6 respectively. It shall be noted that the time entering microgravity condition was set to $0 \mathrm{~s}$.

Under the low input heat flux of $4.68 \mathrm{~W} \mathrm{~cm}^{-2}$, before entering microgravity condition, bubbles generated, grew and departed continuously from the heating wall, as recorded in video. Due to the buoyancy effect, the nucleate pool boiling was at a steady state 
(a)

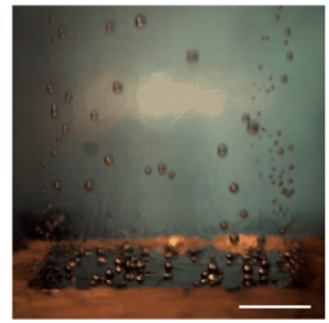

$-0.200 \mathrm{~s}$

(b)

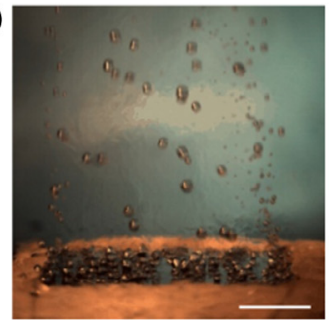

$-0.500 \mathrm{~s}$

(c)

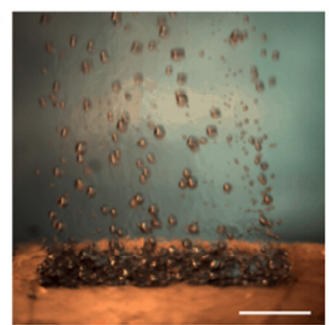

$-0.060 \mathrm{~s}$

(d)

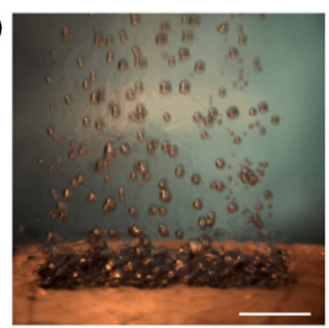

$-0.714 \mathrm{~s}$

(e)

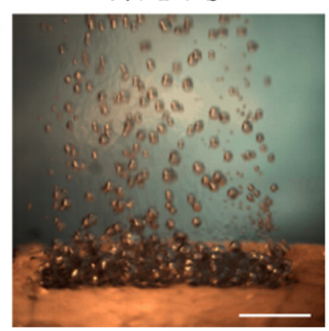

$-0.862 \mathrm{~s}$

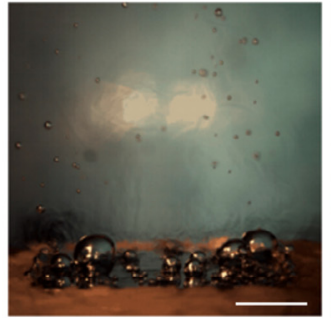

$1.000 \mathrm{~s}$

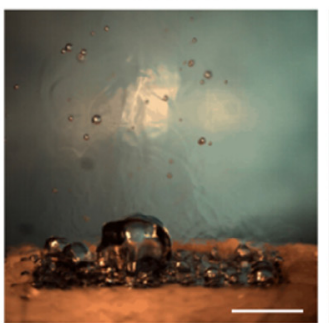

$1.000 \mathrm{~s}$

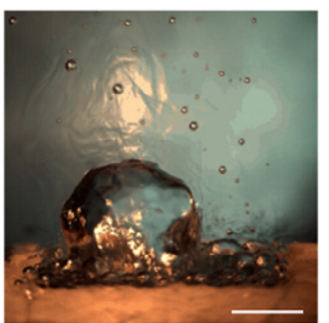

$1.250 \mathrm{~s}$

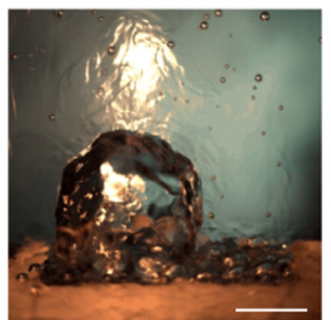

$1.074 \mathrm{~s}$

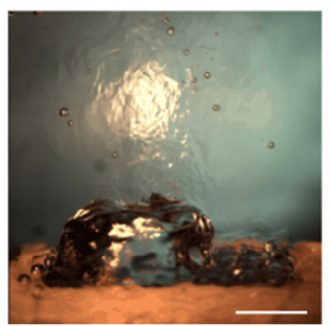

$1.182 \mathrm{~s}$

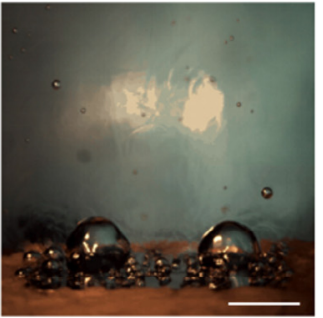

$2.336 \mathrm{~s}$

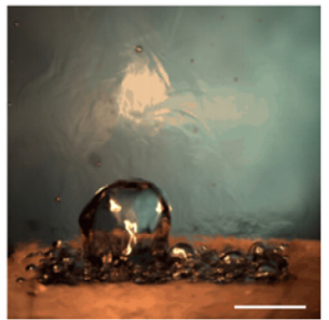

$2.000 \mathrm{~s}$

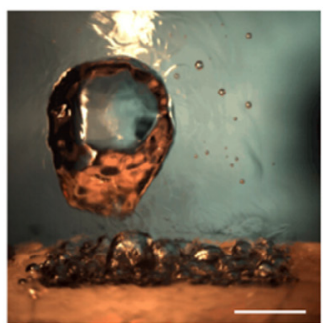

$1.914 \mathrm{~s}$

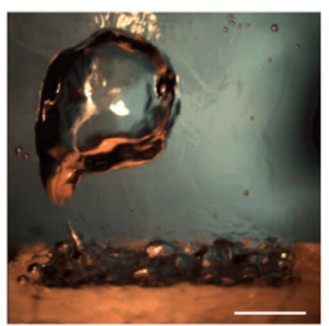

$1.738 \mathrm{~s}$

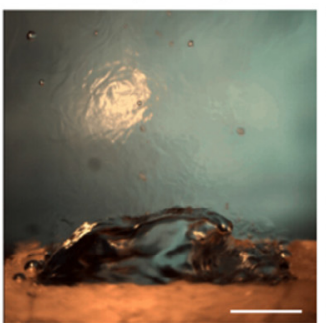

$1.614 \mathrm{~s}$

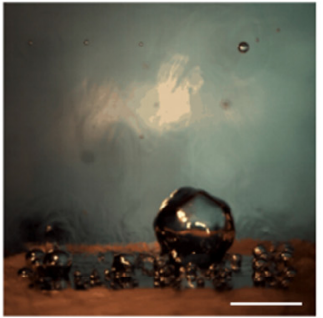

$3.000 \mathrm{~s}$

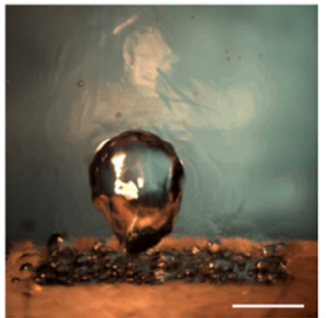

$2.632 \mathrm{~s}$

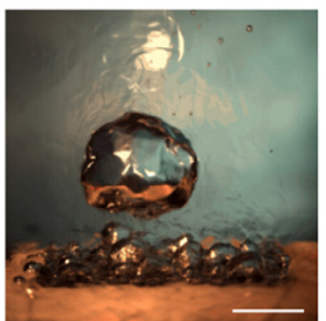

$2.628 \mathrm{~s}$

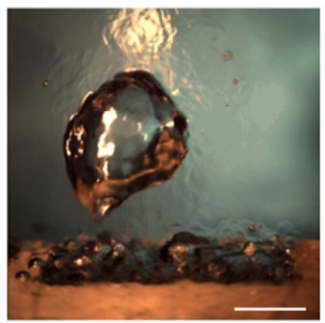

$2.462 \mathrm{~s}$

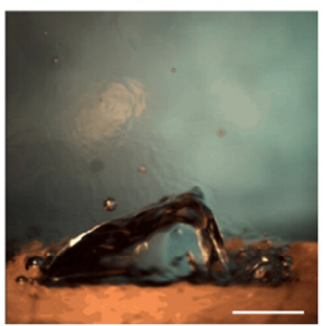

$2.490 \mathrm{~s}$

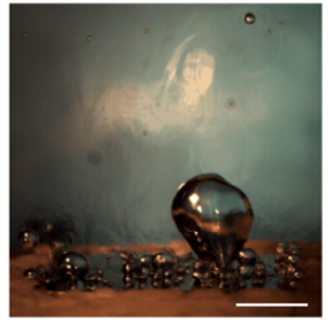

$3.320 \mathrm{~s}$

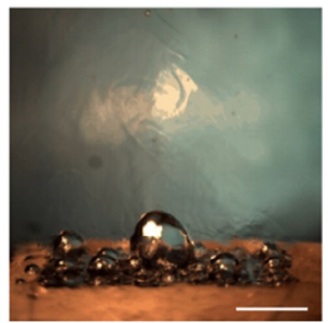

$3.356 \mathrm{~s}$

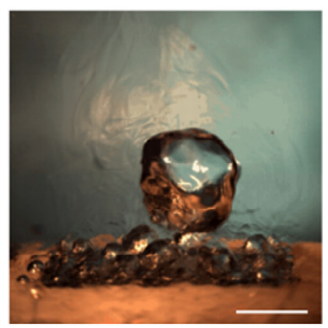

$3.220 \mathrm{~s}$

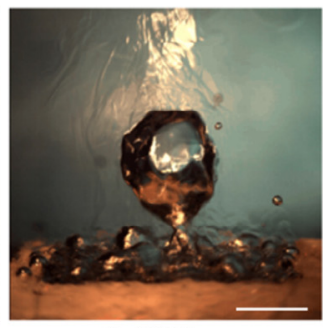

$3.298 \mathrm{~s}$

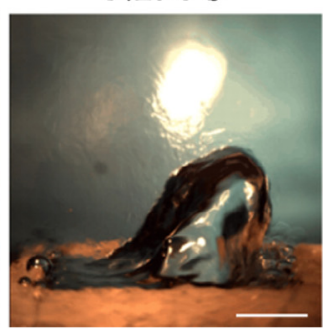

$3.342 \mathrm{~s}$

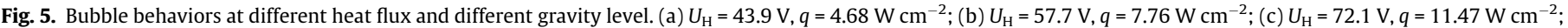
(d) $U_{\mathrm{H}}=83.2 \mathrm{~V}, q=14.74 \mathrm{~W} \mathrm{~cm}^{-2}$; (e) $U_{\mathrm{H}}=91.9 \mathrm{~V}, q=17.55 \mathrm{~W} \mathrm{~cm}^{-2}$ (scale bar: $0.5 \mathrm{~cm}$ ).

and test chip wall temperatures at different locations were kept constant (as shown in Fig. $5 \mathrm{a}$ at $-0.2 \mathrm{~s}$ and in Fig. 6a at -4 to $0 \mathrm{~s}$ ). Nevertheless, after entering microgravity condition the bubble's behavior was totally different. The primary bubbles generated on heater surface moved freely from their origin to the periphery without detachment, and coalescence occurred among adjacent bubbles, later dual large coalesced bubbles were formed around $1 / 4$ centers of the test chip horizontal symmetry axis. Later on, the above two large coalesced bubbles further merged into a single one (as shown in Fig. 5 a at 3.0 s), which departed from heating surface during microgravity period (at $3.320 \mathrm{~s}$ ) finally. During this process, the phenomenon that primary bubbles slide toward the coalesced one was quite remarkable. This movement was defined as bubble migration by Lee [19] and the measured velocity was about $2.5 \mathrm{~cm} / \mathrm{s}$. The slipping motion was also observed in normal gravity by Duursma et al. [20], which could be explained by a micro-wedge model [21] (as shown schematically in Fig. 7). Although bubbles' behavior changed dramatically with gravity reduction, heater surface temperatures in Fig. 6 remained nearly constant or even a maximum decrease of around $3{ }^{\circ} \mathrm{C}$ occurred, indicating that with reduction of gravity, the heat transfer performance was slightly enhanced in low heat flux region compared 

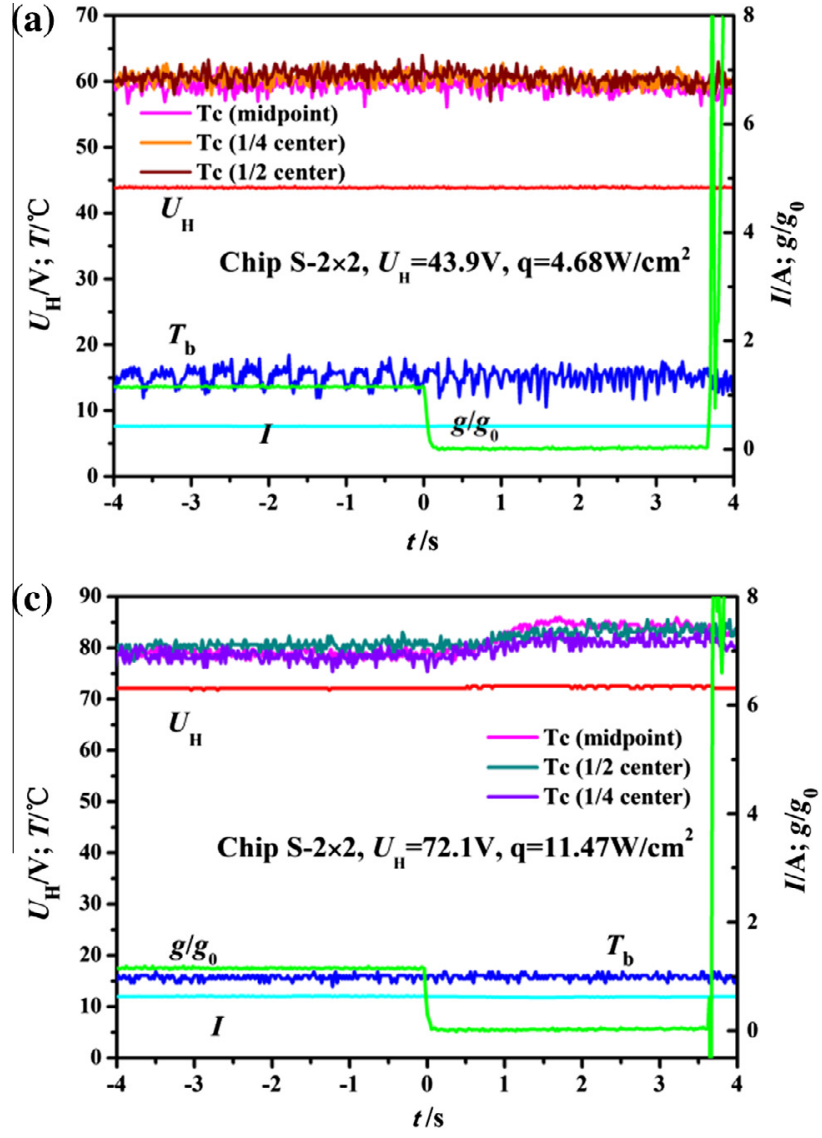
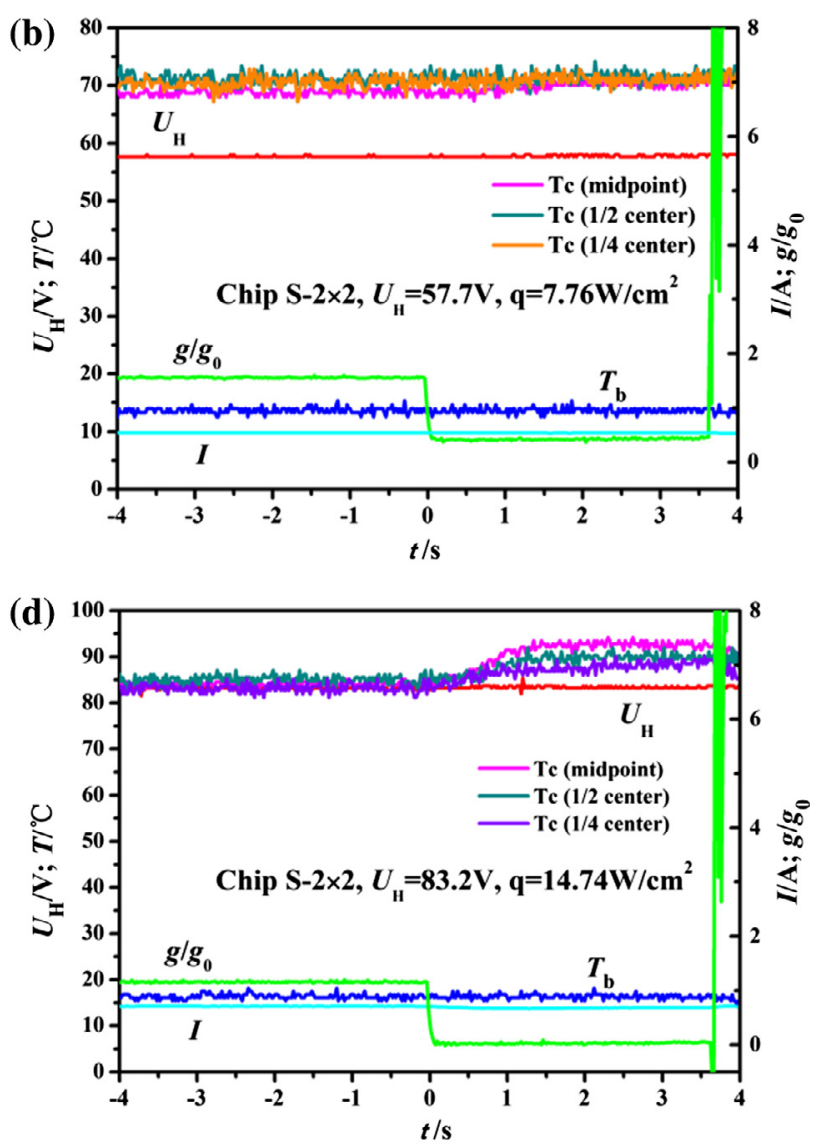

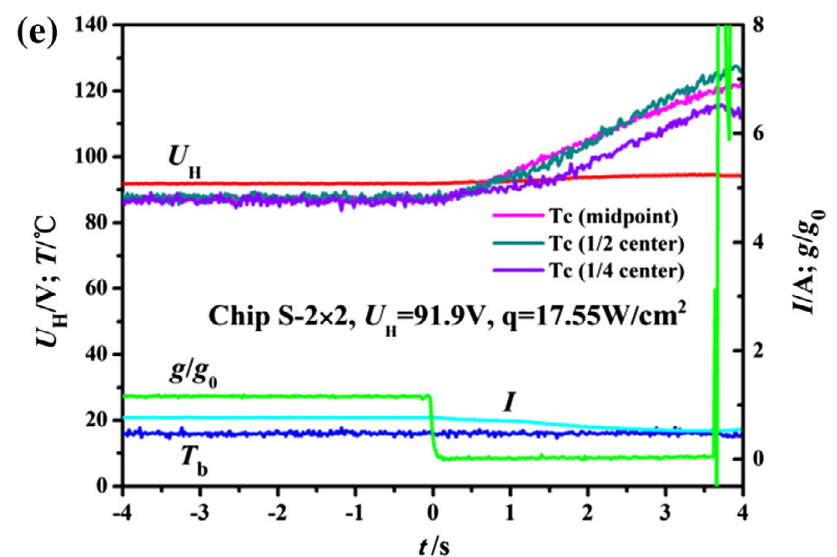

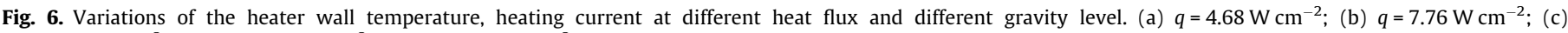
$q=11.47 \mathrm{~W} \mathrm{~cm}^{-2}$; (d) $q=14.74 \mathrm{~W} \mathrm{~cm}^{-2}$; (e) $q=17.55 \mathrm{~W} \mathrm{~cm}^{-2}$.

with that in normal gravity. Merter [22], Xue [23] and Zhang [24] also observed the enhancement, which may be due to the following reasons: First, bubbles were isolated at low heat flux, so there were large spaces between adjacent bubbles, in which bulk liquid can directly cool down the heater surface. Second, under the high subcooling condition of $41 \mathrm{~K}$, a notable temperature gradient around coalesced bubble was formed, bringing about a strong Marangoni convection. It carried warm liquid away from the heater surface vicinity, and delivered cold liquid from bulk to liquid-vapor interface, ensuring access of fresh cold bulk liquid to heater surface [25] (as shown in Fig. 8). Third, fast bubble migration motions enhanced microconvection heat transfer performance by perturbing the liquid around bubble and disrupting the background natural convection boundary layer [26]. In experiment chip
S $1 \times 1$ was used as heating element [17], the improvement in heat transfer performance in microgravity was also observed at input heat flux of $4.74 \mathrm{~W} \mathrm{~cm}^{-2}$. Though absorption and evaporation processes sustained, no coalesced bubble departed in microgravity.

For a moderate input heat flux of $7.76 \mathrm{~W} \mathrm{~cm}^{-2}$, in normal gravity, vapor bubble behavior were the same as in the case mentioned above in Fig. 4a, except that the number of bubbles as well as their sizes increased with heat flux. In microgravity, the primary bubbles merged with each other vigorously, and soon a relatively larger bubble was formed (as shown in Fig. $5 \mathrm{~b}$ at $1.0 \mathrm{~s}$ ). Subsequently, the coalesced bubble size was rapidly enlarged for evaporation of superheated liquid layer and engulfing smaller bubbles around it, leading to a much larger coalesced bubble's formation and departure (as shown in Fig. 5b at 2.632 s). Later, a normal ebullition cycle 


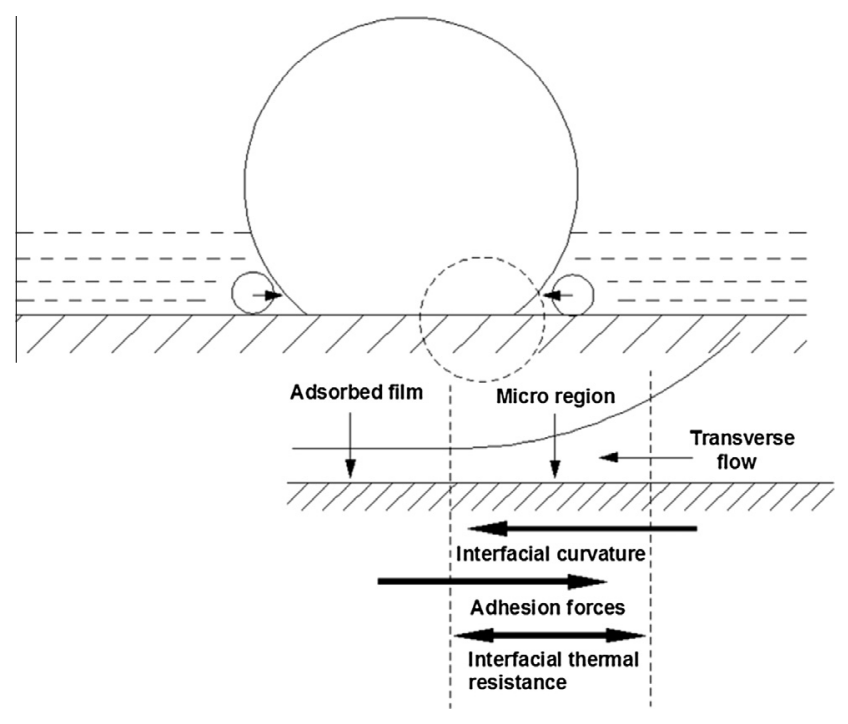

Fig. 7. Schematic diagram of the micro-wedge model.

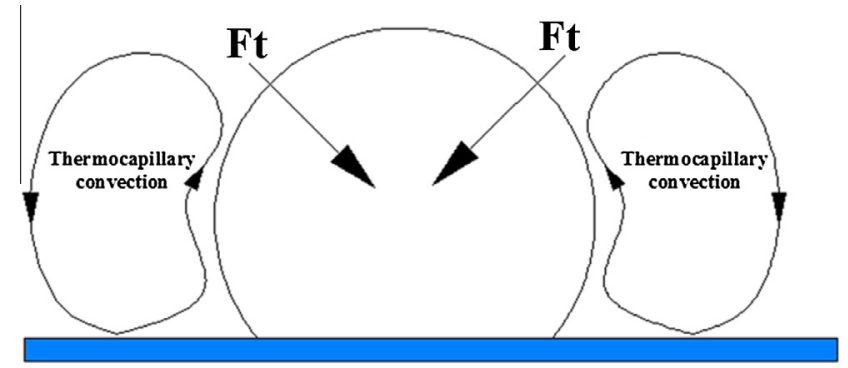

Fig. 8. Schematic diagram of thermocapillary convection mechanism. $F_{\mathrm{t}}$ refers to the reaction force resulted from thermocapillary convection.

consisting of bubble generation, growth and coalescence was repeated on heater surface, and hence steady state nucleate pool boiling can be obtained in microgravity. As seen in Fig. 6b, the wall temperature of chip remained consistent at different gravity levels. It was identical with the heat transfer performance in experiments using chip S $1 \times 1$ at $7.42 \mathrm{~W} \mathrm{~cm}^{-2}$ [17], indicating that in moderate heat flux boiling heat transfer is insensitive to gravity reduction. This may mainly result from primary heat transfer mechanisms such as micro-layer evaporation beneath bubble base, which made up the deterioration of heat transfer for absence of buoyancy force in microgravity.

By further increasing input heat flux to the fully developed nucleate boiling region of $q=11.47 \mathrm{~W} \mathrm{~cm}^{-2}$ and $q=14.74 \mathrm{~W} \mathrm{~cm}^{-2}$ (as shown in Fig. 5c and d), after entering microgravity condition, a large bubble developed very quickly on the heater wall (as shown in Fig. $5 \mathrm{c}$ at $1.250 \mathrm{~s}$ and Fig. $5 \mathrm{~d}$ at $1.074 \mathrm{~s}$ ). As thermocapillary convection results in a reaction force, the coalesced bubble did not detach from chip wall immediately, until growing up to a certain size, the detachment of coalesced bubble occurred, and several smaller merged bubbles detached from the heater wall subsequently (as shown in Fig. $5 \mathrm{c}$ at $2.628 \mathrm{~s}, 3.220 \mathrm{~s}$ for $11.47 \mathrm{~W} \mathrm{~cm}^{-2}$, and in Fig. 5d at $2.462 \mathrm{~s}, 3.298 \mathrm{~s}$ for $14.74 \mathrm{~W} \mathrm{~cm}^{-2}$ respectively). Bubble departure mainly owes to the oscillation caused by lateral coalescence and vertical coalescence of satellite bubbles [17,27], thermocapillary flow generated from surrounding primary bubbles, and surface tension for maintaining a spherical shape also provided driving force to depart in "bouncing ball" effect [28]. Though the large coalesced bubble departed from heater surface, heater wall temperature arose gradually with time since entering microgravity condition. When the first detachment of large coalesced bubble emerged, heater wall temperature reached its maximum peak and then remained constant, which indicated that a quasi-steady state nucleate heat transfer was achievable in microgravity. However, the heat transfer performance was deteriorated. The rise of heater wall temperature in microgravity was directly related to the dry ratio of the heating wall [24,29]. Moreover, the value of temperature rise increased with heat flux (as observed in Fig. $6 c$ and d) due to primary bubbles on heater surface were able to suppress activation of cavities in the surrounding [30]. Number of primary bubbles increased with heat flux, so the suppressant effect was more intense in higher heat flux. Therefore, with increasing input heat flux, the evaporation under coalesced bubble was gradually weakened while extension of dry patches was strengthened in microgravity. For chip $S 1 \times 1$ [17], during the microgravity period, only one large coalesced bubble departed from the chip wall at the input heat flux of $11.59 \mathrm{~W} \mathrm{~cm}^{-2}$. Before departure, heater wall temperature increased by $10^{\circ} \mathrm{C}$ compared to that under normal gravity condition, which was higher than the temperature rise for chip S $2 \times 2$ at $11.47 \mathrm{~W} \mathrm{~cm}^{-2}$ (about $5{ }^{\circ} \mathrm{C}$ ). Moreover, at $14.5 \mathrm{~W} \mathrm{~cm}^{-2}$ local dryout or transition to film boiling occurred on chip S $1 \times 1$ in microgravity, while for chip $S$ $2 \times 2$ a quasi-steady state heat transfer is still achievable.

At very high heat flux of $q=17.55 \mathrm{~W} \mathrm{~cm}^{-2}$, the bubble's behavior is significantly different from before, and reduction of gravity has a remarkable effect on boiling heat transfer (as shown in Figs. 5e and 6e). It can be found that a large coalesced bubble was formed on the heater wall with a large contact area (as shown in Fig. 5e at $1.182 \mathrm{~s}$ ), leading to continuous increase in heater wall temperature (as shown in Fig. 6e). Because of higher levels of subcooling, the coalesced bubble cap was condensed in the bulk liquid, and the contour of coalesced bubble was smoothened as shown in Fig. $5 \mathrm{e}$ at $1.614 \mathrm{~s}$. The volume of large bubble gradually shrunk with time, which mainly attributed to the fact that condensation at the bubble cap was stronger than evaporation under bubble base. At around $3.3 \mathrm{~s}$, drop capsule leaned on one side, and hence the coalesced bubble moved from origin (as shown in Fig. 5e at $3.342 \mathrm{~s}$ ). As seen in videos, the heater surface was blanketed with a vapor film and no nucleation bubbles were observed under the film. Therefore, removal of input heat flux on chip surface became rather difficult. Consequently, a remarkable deterioration of boiling heat transfer occurred as observed in Fig. 5e. It was speculated that the transition to film boiling occurred at the large coalesced bubble base.

In microgravity, though variations of heater wall temperature on chip $S 1 \times 1$ [17] at input heat flux of $14.5 \mathrm{~W} \mathrm{~cm}^{-2}$ were very similar with that on chip S $2 \times 2$ at $17.55 \mathrm{~W} \mathrm{~cm}^{-2}$, the boiling patterns were totally different in both cases. In microgravity duration, a smooth hemispherical bubble was generated on the wall of chip $S$ $1 \times 1$, while on chip $S 2 \times 2$ an oblate vapor blanket was formed. That may indicate that due to the effect of heater size, nucleate boiling heat transfer mechanisms were different in both experiments.

\subsection{Bubble departure radius}

Bubble departure diameter is an important parameter for boiling heat transfer performance. Under reduced gravity condition, bubble behaviors are completely different from those in normal gravity, thus only the bubble departure diameter in microgravity is considered in this paper.

Experimental conditions in this research were almost the same as those in experiments carried out by Xue et al. [17], except the heater size. Fig. 9 shows the bubble departure radii of chip $\mathrm{S} 2 \times 2$ and chip $\mathrm{S} 1 \times 1$ in microgravity. Five test runs at five different input heat fluxes were carried out by Xue, for input heat 

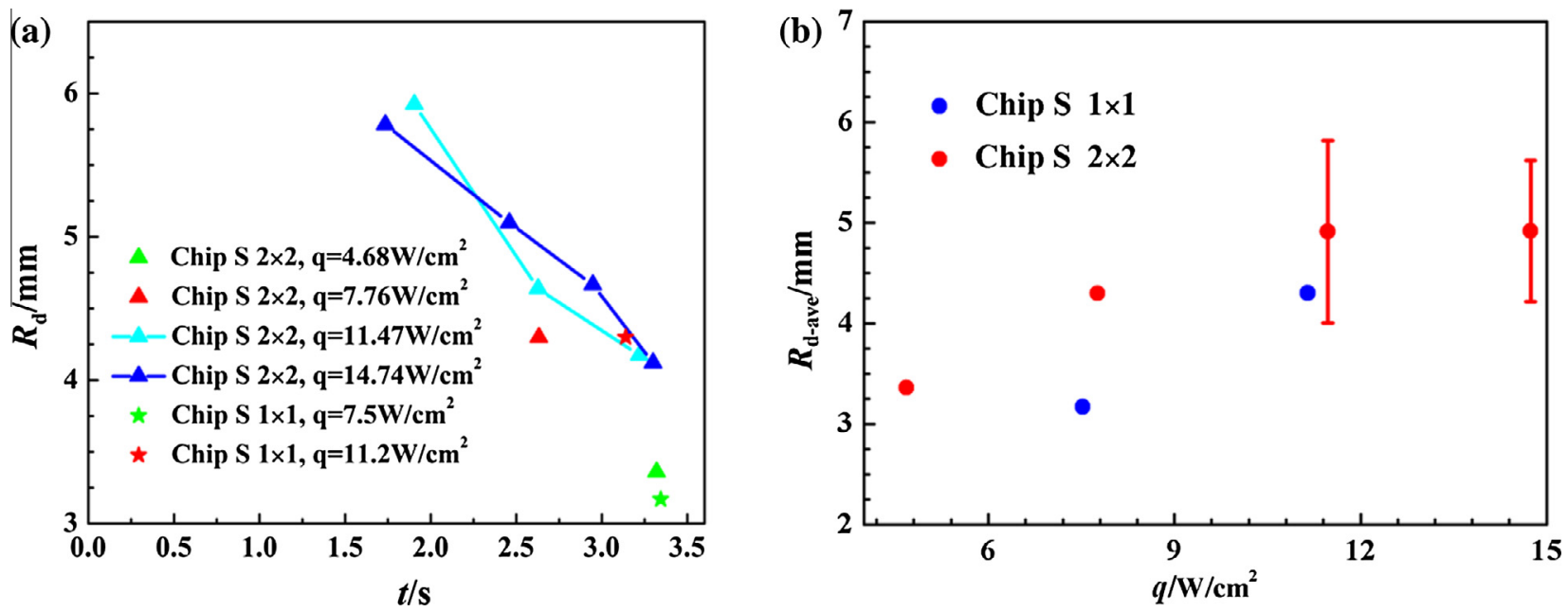

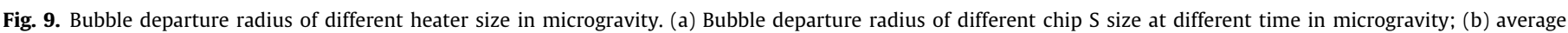
bubble departure radius of different chip S size under different heat fluxes in microgravity.

fluxes of $3.1 \mathrm{~W} \mathrm{~cm}^{-2}$ and $4.7 \mathrm{~W} \mathrm{~cm}^{-2}$, merged bubbles attached to the heater surface without detachment during the whole microgravity period. With increasing input heat flux, only one large coalesced bubble departed from the heating wall for both input heat fluxes of $7.5 \mathrm{~W} \mathrm{~cm}^{-2}$ and $11.2 \mathrm{~W} \mathrm{~cm}^{-2}$ during $3.6 \mathrm{~s}$. Under input heat flux of $14.8 \mathrm{~W} \mathrm{~cm}^{-2}$, a coalesced hemispherical bubble formed rapidly, and covered the chip wall completely. Hence only bubble departure radii at $7.5 \mathrm{~W} \mathrm{~cm}^{-2}$ and $11.2 \mathrm{~W} \mathrm{~cm}^{-2}$ on chip $\mathrm{S} 1 \times 1$ were analyzed. However, in five test runs using chip $\mathrm{S} 2 \times 2$ as heater surface, detachments of merge bubble took place in the first four test runs except the highest heat flux one.

As shown in Fig. 9a, moment of the first departure of large coalescence bubble from chip S $2 \times 2$ was advanced with the increase in input heat flux. The evaporation of working fluid increases linearly with heat flux at a given liquid subcooling [27], which leads to a more rapid formation and subsequent departure of coalesced bubble from the chip wall. The same regular pattern was also revealed on chip $S 1 \times 1$. In addition, an interesting phenomenon emerged on chip $S 2 \times 2$ for input heat fluxes of $11.47 \mathrm{~W} \mathrm{~cm}^{-2}$ and $14.74 \mathrm{~W} \mathrm{~cm}^{-2}$ : As the large bubble left from the heater wall and gradually rose up to bulk liquid, a quick upward liquid flow was formed behind the bubble. For average temperature of the heater wall much higher than that of subcooled bulk liquid, thus an upward natural convection flow arose above the test chip. After the departure of first coalesced bubble, next coalesced bubble was formed immediately by violent merging of primary bubbles. During the rapid growth period of the second coalesced bubble, the liquid directly above the bubble was pushed away, which accelerated the inherent upward bulk flow. Therefore, a quick upward liquid flow emerged between the departure bubble and next large coalesced bubble. The accelerated flow generated an upward force on the next merged bubble (as shown in Fig. 10), which was not yet prepared to detach and was still attached to heater surface, resulting in the departure of a smaller-sized coalesced bubble. It was indicated that the departure of the former coalesced bubble has a great influence on the latter one, leading to a smaller bubble departure radii afterwards as observed in Fig. 9a.

Fig. 9b shows the average bubble departure radius of chip $S 2 \times 2$ and chip $S 1 \times 1$ under different input heat fluxes in microgravity, because only one bubble detached from heater surface during the whole microgravity period for chip $S 1 \times 1$ at input heat fluxes of $7.5 \mathrm{~W} \mathrm{~cm}^{-2}$ and $11.2 \mathrm{~W} \mathrm{~cm}^{-2}, 4.68 \mathrm{~W} \mathrm{~cm}^{-2}$ and $7.76 \mathrm{~W} \mathrm{~cm}^{-2}$ for chip S $2 \times 2$, the corresponding standard deviation of average bubble departure radius was not marked in Fig. 9b. As

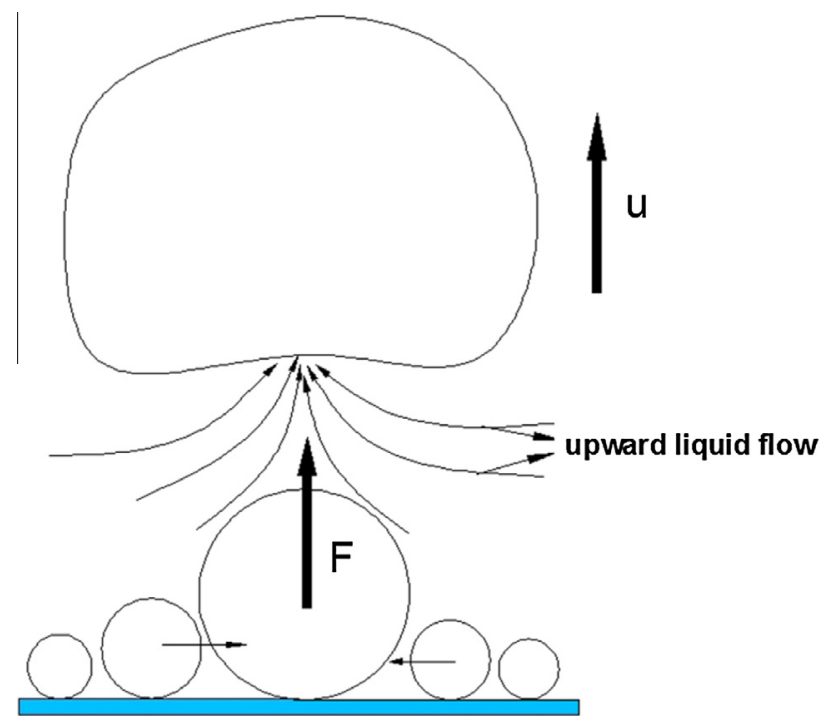

Fig. 10. Schematic diagram of the departure effect of the former coalesced bubble on the latter one; $F$ refers to the force caused by the upward liquid flow.

seen in the figure, the departure of coalesced bubble took place at the smallest input heat flux of $4.68 \mathrm{~W} \mathrm{~cm}^{-2}$ for chip $\mathrm{S} 2 \times 2$, lower than that of $7.5 \mathrm{~W} \mathrm{~cm}^{-2}$ for chip $\mathrm{S} 1 \times 1$, and the highest input heat flux of $14.74 \mathrm{~W} \mathrm{~cm}^{-2}$, higher than that of $11.2 \mathrm{~W} \mathrm{~cm}^{-2}$ for chip $S 1 \times 1$. In addition, in a roughly same heat flux range, chip $\mathrm{S} 2 \times 2$ exhibited a larger bubble departure radius compared with chip $\mathrm{S} 1 \times 1$.

Generally, the superheated zone above the heating wall enlarges with heater size, and growth of vapor bubble mainly restricts within the superheated region because condensation takes place outside the superheated region. Many experimental, analytical, and numerical results have indicated that most of energy required for bubble growth came from the superheated liquid layer around a bubble [26]. Therefore, at the input heat flux of $4.68 \mathrm{~W} \mathrm{~cm}^{-2}$, the thicker superheated liquid layer on chip $\mathrm{S} 2 \times 2$ can provide enough energy for coalesced bubble to grow up to the departure size. And in the same heat flux region, bubbles on chip $S 2 \times 2$ can absorb more energy from the superheated liquid layer around it compared with those on chip $S 1 \times 1$, thus a larger bubble departure radius was observed. The spatial temperature 
distributions on chip S $2 \times 2$ were more inhomogeneous than those on chip $S 1 \times 1$, leading to nucleation sites at different locations being activated in different heat flux regions. At the high input heat flux of $14.74 \mathrm{~W} \mathrm{~cm}^{-2}$, the periphery of chip S $2 \times 2$ started to dissipate input heat, providing persistent vapor source for large coalesced bubble formation and departure. Nevertheless, wall temperatures of chip $S 1 \times 1$ were quite uniform, so the extents of nucleation sites being activated were nearly the same at different locations. In microgravity, with increase in the input heat flux, chip $S 1 \times 1$ gradually activated the nucleation site to remove the input heat, thus at very high input heat flux region there were no more nucleation sites for evaporation and thus no bubble departed.

It can be observed that for chip $S 2 \times 2$, the average bubble departure radii increased linearly with the input heat flux from $4.68 \mathrm{~W} \mathrm{~cm}^{-2}$ to $11.47 \mathrm{~W} \mathrm{~cm}^{-2}$, while remained almost same from $11.47 \mathrm{~W} \mathrm{~cm}^{-2}$ to $17.55 \mathrm{~W} \mathrm{~cm}^{-2}$. On the one hand, evaporation of working fluid increased linearly with heat flux, bringing a larger merged bubble in the higher input heat flux region. On the other hand, the Marangoni force $F_{\mathrm{M}}$ generated from reaction force of Marangoni convection pushed bubble toward heater wall, preventing it from detaching. The force can be expressed as follows:

$F_{\mathrm{M}}=\zeta\left|\frac{d \sigma}{d T}\right| \Delta T_{\mathrm{cb}} \pi R_{\mathrm{d}}$

where $\xi$ is a constant, $R_{\mathrm{d}}$ is bubble radius and $\sigma$ is surface tension. $\Delta T_{\mathrm{cb}}$ denotes the temperature difference between chip wall and bulk liquid, while bulk liquid temperature was fixed at around $15^{\circ} \mathrm{C}$ in the experiment, thus the Marangoni force $F_{\mathrm{M}}$ is proportional to wall temperature. The heater wall temperature increased with heat flux as shown in Fig. 6, thus the negative force $F_{M}$ got larger with the increase in input heat flux, leading to a longer growth period and a bigger departure diameter. Therefore, the average bubble departure radius increased with the input heat flux at first. However, in high input heat flux region, the size of departure bubble was nearly the same as that of chip S, which did not further increase with the input heat flux due to the heater surface perimeters' restriction.

\subsection{Boiling curve in different gravities}

The ground experiment was already conducted with the same experimental installation as that of microgravity tests to validate reliability of the test system, and confirm the heat flux range studied in microgravity experiment. In this paper, the average temperature of $T_{\mathrm{c} 1}, T_{\mathrm{c} 1 / 2}$ and $T_{\mathrm{c} 1 / 4}$ represented the reference wall temperature of chip $S 2 \times 2$. Fig. 11 describes boiling curves of chip $S 2 \times 2$ at different gravity levels, where black, red ${ }^{1}$ and blue solid color circles denote experimental results in ground gravity, normal gravity before drop capsule release, and microgravity conditions respectively. It was found that for chip S $2 \times 2$ an excellent agreement was quite obvious between normal gravity data points and the ground test curve, guaranteeing the repeatability and reliability of data points.

As seen in Fig. 11, in low input heat flux region, heat transfer performance of chip S $2 \times 2$ slightly improved under microgravity condition as compared with that under normal gravity. In moderate input heat flux, heater wall temperature remained almost constant in normal gravity and microgravity conditions, indicating that heat transfer performance was independent of gravity levels. Further increasing heat flux to high heat flux region, the slope of boiling curve in microgravity was obviously smaller than that in normal gravity, and heater surface temperature was gradually

\footnotetext{
${ }^{1}$ For interpretation of color in Figs. 11 and 13, the reader is referred to the web version of this article.
}

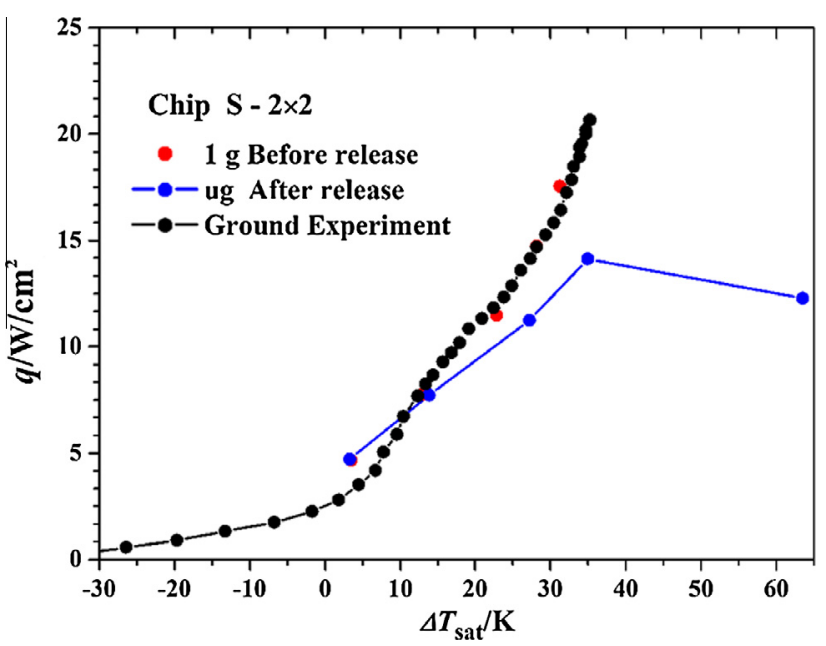

Fig. 11. Boiling curves of chip S $2 \times 2$ in different gravity levels.

higher than that in normal gravity. Although continuous departure of large coalesced bubble occurred on chip's wall, different degrees of dryout have been developed on the coalesced bubble base. In very high input heat flux region, a much striking deterioration of heat transfer performance was observed, and the heater wall temperature was significantly higher than that in normal gravity. According to video records, a vapor film blanket finally formed on heater wall, indicating the emergence of transition to film boiling on large coalesced bubble base in microgravity.

Pool boiling curves using chip S $1 \times 1$ [17] and chip $S 2 \times 2$ are plotted in Fig. 12 for comparison. The heating method used in the smaller heater size experiment was constant heating current, and in current study was constant heating voltage method. A large number of terrestrial experiments showed that different heating methods had no effect on pool boiling curves and $q_{\mathrm{cHF}}$ values, so it was deemed that heating methods didn't affect pool boiling heat transfer performance in microgravity either. It should be pointed out that pool boiling heat transfer at the highest input heat flux was in an unsteady state in both experiments, thus dash dot lines were used to connect the last data point with the other.

In ground experiment, chip S $2 \times 2$ and chip $S 1 \times 1$ followed the same $q$ vs $\Delta T_{\text {sat }}$ rule in natural convection region (from 0 to $2.25 \mathrm{~W} \mathrm{~cm}^{-2}$ ) as seen in Fig. 12, indicating that the heater size of chip $S$ has a negligible impact on natural convection heat transfer performance. Shortly, boiling incipience occurred on chip $S 1 \times 1$ at the input heat flux of $2.25 \mathrm{~W} \mathrm{~cm}^{-2}$, while for chip S $2 \times 2$ the boiling onset occurred later than that on chip $S 1 \times 1$, delaying about $3 \mathrm{~W} \mathrm{~cm}^{-2}$. The delay is due to violent turbulent natural convection heat transfer process carrying out on chip $S 2 \times 2$, which dissipated increased heat flux. Therefore, better heat transfer performance on chip $S 1 \times 1$ than that on chip $S 2 \times 2$ was observable in the input heat flux range of $2.25-3 \mathrm{~W} \mathrm{~cm}^{-2}$. In input heat flux range greater than $3 \mathrm{~W} \mathrm{~cm}^{-2}$, chip $\mathrm{S} 1 \times 1$ still showed a much better heat transfer performance than chip S $2 \times 2$. The $q_{\mathrm{CHF}}$ of chip $\mathrm{S} 1 \times 1$ was $28.9 \mathrm{~W} \mathrm{~cm}^{-2}$, greater than $20.655 \mathrm{~W} \mathrm{~cm}^{-2}$ for chip S $2 \times 2$.

In microgravity, the boiling curve of chip $S 2 \times 2$ moved to a higher heater wall temperature compared with chip $S 1 \times 1$, indicating the deterioration of heat transfer with heater size under microgravity condition. Thus, pool boiling heat transfer performance worsened with the increases in heater sizes in both ground and microgravity conditions. However, in microgravity, the characteristic of CHF was entirely different from that in ground condition. In microgravity, the $q_{\mathrm{CHF}}$ of chip S $2 \times 2$ was about $14.13 \mathrm{~W} \mathrm{~cm}^{-2}$, higher than that by chip S $1 \times 1$ (about $11.76 \mathrm{~W} \mathrm{~cm}^{-2}$ ), contrary 


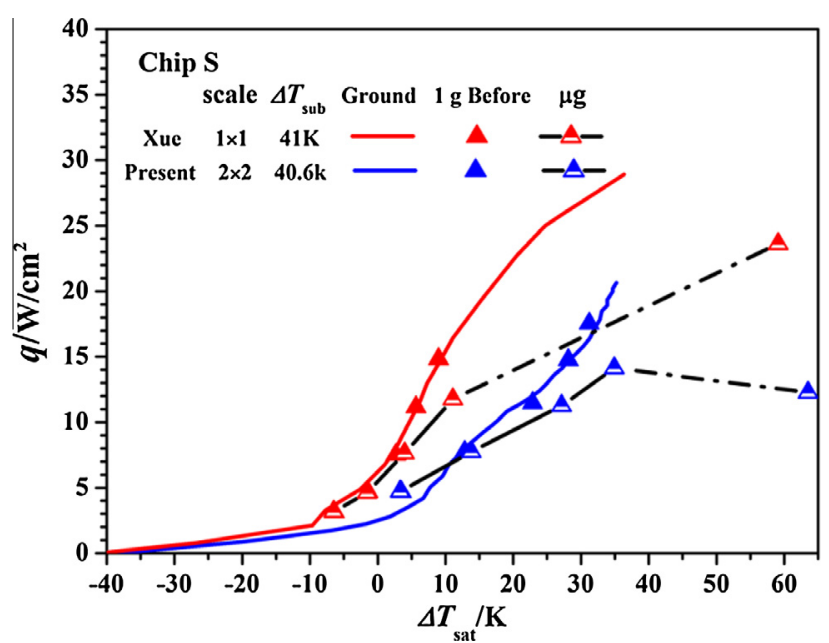

Fig. 12. Boiling curves of chip $S 2 \times 2$ and chip $S 1 \times 1$ in different gravity levels.

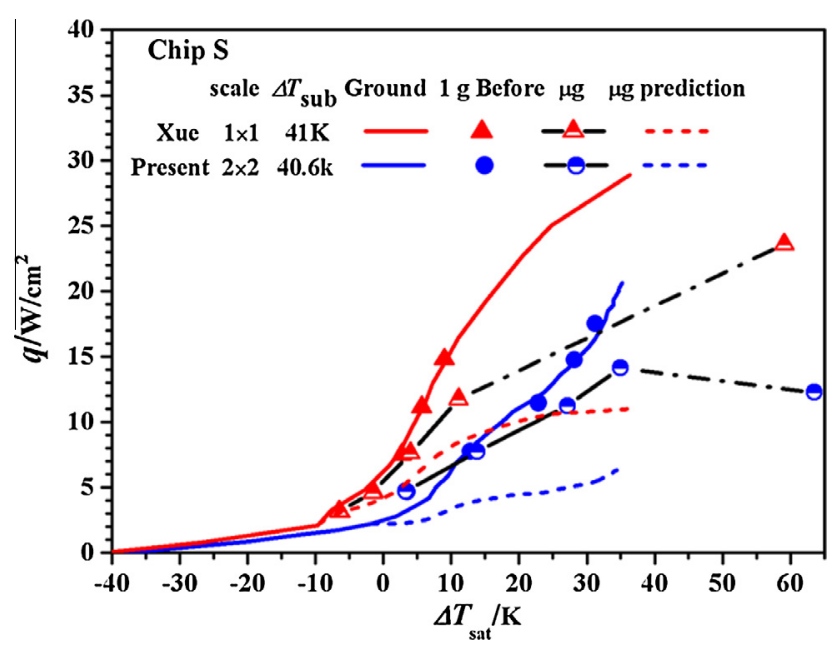

Fig. 13. Experimental pool boiling curves in different gravity along with the microgravity predictions considering $g$-jitter.

to the CHF characteristic in ground condition. The difference is illustrated below. The temperatures at periphery region of chip $\mathrm{S}$ $2 \times 2$ were lower than that at central area at a given heat flux, thus the number of activated nucleation sites at periphery was less than that in the central region. However, on chip $S 1 \times 1$, temperature distribution was more uniform, thus the extents of nucleation sites being activated were nearly same at different locations. Therefore, for a certain heat flux, activated nucleation sites per unite wall area on chip $S 1 \times 1$ were more than those on chip $S 2 \times 2$, leading to differences in nucleate boiling heat transfer coefficient in both microgravity and ground conditions for the two heater sizes. Similarly, the $q_{\mathrm{CHF}}$ on chip S $2 \times 2$ was lower than that on chip $S 1 \times 1$ in ground condition. However, in microgravity, heat removal from chip wall got hard for absence of buoyance, to overcome the trouble, chip S $1 \times 1$ continuously activated nucleation sites along with increase in input heat flux, thus finally at about $11.76 \mathrm{~W} \mathrm{~cm}^{-2}$ there were no more nucleation sites for evaporation and $\mathrm{CHF}$ occurred. However, for chip S $2 \times 2$, activation of nucleation sites at periphery delayed to higher input heat flux. Thus for very high input heat flux, nucleation sites at periphery of chip $S 2 \times 2$ were activated, where continuous evaporation occurred, preventing the heater surface to burn out.
The threshold acceleration $a_{\text {tran }}$ demarcated the boundary between surface tension and buoyancy dominated boiling regime can be calculated as follows [16]:

$\frac{L_{\mathrm{h}}}{L_{\mathrm{c}}}=\frac{L_{\mathrm{h}}}{\sqrt{\frac{\sigma}{\left(\rho_{1}-\rho_{\mathrm{v}}\right) a_{\text {tran }}}}}=2.1 \Rightarrow a_{\text {tran }}=\frac{4.41 \sigma}{L_{\mathrm{h}}^{2}\left(\rho_{\mathrm{l}}-\rho_{\mathrm{v}}\right)}$

The values of $a_{\text {tran }} / g_{\mathrm{e}}$ in experiments using chip S $1 \times 1$ and chip S $2 \times 2$ as heaters were 0.0211 and 0.0053 respectively. After calculations, the practical $\mu \mathrm{g} / \mathrm{g}_{\mathrm{e}}$ value in microgravity was bigger than the threshold $a_{\text {tran }} / g_{\mathrm{e}}$ values for chip S $2 \times 2$ but smaller than that for chip $S 1 \times 1$, therefore after drop capsule release, the boiling performance was dominated by buoyancy for chip $S 2 \times 2$, but dominated by surface tension for chip $S 1 \times 1$, which proved the previous speculation in different boiling pattern portions. Moreover, the $L_{\mathrm{h}} / L_{\mathrm{c}}$ for chip $S 2 \times 2$ and chip $S 1 \times 1$ were 2.89 and 1.45 respectively. Therefore, it was found that the range of transition heater size criteria is $1.45<\frac{L_{\mathrm{h}}}{L_{\mathrm{c}}}<2.89$ in the present work.

Recently, Raj and Kim [16] put forward an updated model based on high quality microgravity data $\left(a / g_{\mathrm{e}}<10^{-6}\right)$, which accurately predicted experimental microgravity data. Thus, we used the model to predict pool boiling heat flux in microgravity $\left(q_{2}\right)$ from the corresponding earth gravity data $\left(q_{1}\right)$. Heat fluxes in microgravity on chip $S 2 \times 2$ and chip $S 1 \times 1$ can be simulated by using Eqs. (14) and (15) respectively:

$q_{2}=q_{1} \times\left(\frac{\mu_{\mathrm{g}}}{g_{\mathrm{e}}}\right)^{\mathrm{m}_{\mathrm{BDB}}}$

$q_{2}=q_{1} \times 0.02107703^{\mathrm{m}_{\mathrm{BDB}}} \times 0.99998$

In Fig. 13, short dash lines in red and blue colors respectively denote predicted pool boiling curves in microgravity in studies on chip $S 1 \times 1$ and chip $S 2 \times 2$. It was seen that experimental values were generally higher than predicted values in both experiments, and the difference was more evident for chip $S 2 \times 2$. The subcooling condition in the experiment was $41 \mathrm{~K}$, significantly greater than 11-27 K in studies carried out by Raj and Kim, bringing about higher experimental results compared with the predicted values. The continuously fluctuated gravity levels ( $g$-jitter) also had a contribution to the difference [1,31], which could result in continuous adjustments in bubble shape, increasing heat transfer through producing flow around the bubble [16]. Besides, larger primary bubbles were more sensitive to $g$-jitter [32]. Therefore, a higher heat transfer enhancement was formed in microgravity experiment for chip $S 2 \times 2$, and a larger bias between the experimental values and predicted values occurred.

\section{Conclusions}

Experiments were conducted in both short-term microgravity and earth gravity conditions to study the effects of heater size and gravity level on nucleate pool boiling, and the results were compared with previously published data of chip $S 1 \times 1$, the main conclusions are listed as follows:

(1) For chip S $2 \times 2$, the departure of coalesced bubble took place at a wider input heat flux range than that for chip $S 1 \times 1$. And the average bubble departure radii increased with the input heat flux linearly from $4.68 \mathrm{~W} \mathrm{~cm}^{-2}$ to $11.47 \mathrm{~W} \mathrm{~cm}^{-2}$, but remained constant from $11.47 \mathrm{~W} \mathrm{~cm}^{-2}$ to $17.55 \mathrm{~W} \mathrm{~cm}^{-2}$. Compared with chip S $1 \times 1$, chip S $2 \times 2$ showed a larger bubble departure radius at a same heat flux. Moreover, for chip $S 2 \times 2$, the departure of former coalesced bubble had 
an important effect on the next merged bubble which was not ready to detach, leading to a continuous smaller bubble departure radii afterwards.

(2) The nucleate boiling heat transfer performance deteriorated with increases in heater sizes in both earth gravity and microgravity conditions. However, in microgravity, the $q_{\mathrm{CHF}}$ of chip S $2 \times 2$ was $20 \%$ greater than that of chip S $1 \times 1$, contrary to the CHF characteristic in earth ground condition.

(3) In a very high heat flux region, a smooth hemispherical bubble generated on the wall of chip $S 1 \times 1$ in microgravity, while on the chip S $2 \times 2$ an oblate vapor blanket formed, which indicates that boiling heat transfer mechanisms were different in both cases because of different heater sizes. It was found according to calculation that in microgravity, the boiling performance was dominated by buoyancy for chip $S 2 \times 2$, but it was dominated by surface tension for chip $S 1 \times 1$, verifying the above speculation. Moreover, the range of transition heater size criteria in the present work was $1.45<\frac{L_{h}}{L_{c}}<2.89$.

(4) By using the updated model developed by Raj and Kim, it was discovered that the predicted values were generally lower than experimental values in both experiments, and the deviations were more evident for chip S $2 \times 2$. The difference in subcooling conditions between our experiments and the study by Raj and Kim, continuously g-jitter may bring about differences between experimental and predicted results. Furthermore, larger primary bubbles were more sensitive to $g$-jitter. Therefore, larger differences were observed in the experiment by using chip $S 2 \times 2$.

\section{Acknowledgements}

The authors gratefully appreciate the financial supports from the project of National Natural Science Foundation of China (No. 51225601) and the Key Laboratory of Microgravity/CAS for experiments utilizing the drop tower Beijing.

\section{References}

[1] P.D. Marco, W. Grassi, Pool boiling in microgravity: assessed results and open issues, in: Third European Thermal-Sciences Conference, 2000, pp. 10-13.

[2] N. Bakhru, J.H. Lienhard, Boiling from small cylinders, Int. J. Heat Mass Transfer 15 (1972) 2011-2025.

[3] C.D. Henry, J. Kim, A study of the effects of heater size, subcooling, and gravity level on pool boiling heat transfer, Int. J. Heat Fluid Flow 25 (2004) 262-273.

[4] R. Raj, J. Kim, J. McQuillen, Gravity scaling parameter for pool boiling heat transfer, J. Heat Transfer 132 (2010) 091502.

[5] R. Raj, J. Kim, J. McQuillen, Subcooled pool boiling in variable gravity environments, J. Heat Transfer 131 (2009) 091502.

[6] R. Raj, J. Kim, Heater size and gravity based pool boiling regime map: transition criteria between buoyancy and surface tension dominated boiling, J. Heat Transfer 132 (2010) 091503.
[7] J.H. Lienhard, V.K. Dhir, Hydrodynamic prediction of peak pool-boiling heat fluxes from finite bodies, J. Heat Transfer 95 (1973) 152-158.

[8] W.M. Rohsenow, A method of correlating heat transfer data for surface boiling of liquids, Trans. ASME 84 (1962) 969-976.

[9] M.G. Cooper, Saturation nucleate pool boiling - a simple correlation, Inst. Chem. Eng. Symp. 86 (1984) 785-793.

[10] K. Stephan, M. Abdelsalam, Heat-transfer correlations for natural convection boiling, Int. J. Heat Mass Transfer 23 (1980) 73-87.

[11] N. Zuber, Hydrodynamic Aspects of Boiling Heat Transfer, AEC Report AECU4439, 1959.

[12] Y. Haramura, Y. Katto, A new hydrodynamic model of critical heat flux applicable widely to both pool and forced convection boiling on submerged bodies in saturated liquids, Int. J. Heat Mass Transfer 26 (1983) 389-399.

[13] T. Oka, Y. Abe, K. Tanaka, Y.H. Mori, A. Nagashima, Observational study of pool boiling under microgravity, JSME Int. J. Ser. B 35 (1992) 280-286.

[14] T. Oka, Y. Abe, Y.H. Mori, A. Nagashima, Pool boiling of n-Pentane, CFC-113 and water under reduced gravity: parabolic flight experiments with a transparent heater, J. Heat Transfer 117 (1995) 408-417.

[15] R. Raj, J. Kim, J. McQuillen, On the scaling of pool boiling heat flux with gravity and heater size, J. Heat Transfer 134 (2012) 011502.

[16] R. Raj, J. Kim, J. McQuillen, Pool boiling heat transfer on the international space station: experimental results and model verification, J. Heat Transfer 134 (2012) 101504.

[17] Y.F. Xue, J.F. Zhao, J.J. Wei, J. Li, D. Guo, S.X. Wan, Experimental study of nucleate pool boiling of FC-72 on smooth surface under microgravity, Micrograv. Sci. Technol. 23 (2011) 75-85.

[18] J.J. Wei, Experimental Study on Enhanced Boiling Heat Transfer From Silicon Chips with Micro-pin-fins and Submicron-scale Roughness, PhD Dissertation, Kyushu University, 2002.

[19] H.S. Lee, Mechanisms of steady-state nucleate pool boiling in microgravity, Ann. N.Y. Acad. Sci. 974 (2002) 447-462.

[20] G.R. Duursma, F. Jiang, K. Sefiane, S. Duff, H. Beji, On the effects of thermocapillary driven oscillations on bubble growth during boiling of FC72 on a thin wire, Int. J. Therm. Sci. 50 (2011) 1809-1819.

[21] P. Stephan, J. Hammer, A new model for nucleate boiling heat transfer, Heat Mass Transfer 30 (1994) 119-125.

[22] H. Merte, H.S. Lee, R.B. Keller, Dryout and rewetting in the pool boiling experiment flown on STS-72 (PBE-IIB), STS-77 (PBE-IIA), Final Report, NASA Grant NAG-1684, Department of Mechanical Engineering and Applied Mechanics, University of Michigan, Ann Arbor, Michigan, UM-MEAM-98-01, 1998.

[23] Y.F. Xue, J.F. Zhao, J.J. Wei, Y.H. Zhang, B.J. Qi, Experimental study of nucleate pool boiling of FC-72 on micro-pin-finned surface under microgravity, Int. J. Heat Mass Transfer 63 (2013) 425-433.

[24] Y.H. Zhang, J.J. Wei, Y.F. Xue, X. Kong, J.F. Zhao, Bubble dynamics in nucleate pool boiling on micro-pin-finned surfaces in microgravity, Appl. Therm. Eng. 70 (2014) 172-182.

[25] R. Marek, J. Straub, The origin of thermocapillary convection in subcooled nucleate pool boiling, Int. J. Heat Mass Transfer 44 (2001) 619-632.

[26] J. Kim, Review of nucleate pool boiling bubble heat transfer mechanisms, Int. J. Multiphase Flow 35 (2009) 1067-1076.

[27] J. Straub, Boiling heat transfer and bubble dynamics in microgravity, Adv. Heat Transfer 35 (2001) 57-172.

[28] Yu A. Buyevich, B.W. Webbon, Bubble formation at a submerged orifice in reduced gravity, Chem. Eng. Sci. 51 (1996) 4843-4857.

[29] H.S. Lee, H. Merte, F. Chiaramonte, Pool boiling curve in microgravity, J. Thermophys. Heat Transfer 11 (1996).

[30] J.F. Zhao, J. Li, S.F. Wang, Bubble behavior and heat transfer in quasi-steady pool boiling in microgravity, Micrograv. Sci. Technol. 21 (2009) 175-183.

[31] J. Kim, Review of reduced gravity boiling heat transfer: US research, J. Jpn. Soc. Micrograv. Appl. 20 (2003) 264-271.

[32] J. Kim, J.F. Benton, D. Wisniewski, Pool boiling heat transfer on small heaters: effect of gravity and subcooling, Int. J. Heat Mass Transfer 45 (2002) 39193932. 